\title{
Integrating Aerial and Underwater Data for Archaeology: Digital Maritime Landscapes in 3D
}

\author{
Jonathan Benjamin, John McCarthy, Chelsea Wiseman, \\ Shane Bevin, Jarrad Kowlessar, Peter Moe Astrup, \\ John Naumann, and Jorg Hacker
}

\begin{abstract}
Archaeologists have aspired to a seamless integration of terrestrial and marine survey since maritime archaeology began to emerge as a distinct sub-discipline. This chapter will review and discuss how 3D technology is changing the way that archaeologists work, blurring the boundaries between different technologies and different environments. Special attention is paid to the integration of data obtained from aerial and underwater methods. Maritime archaeology is undergoing an explosion of site recording methods and techniques which improve survey, excavation and interpretation, as well as management and conservation of material culture, protected sites, and cultural landscapes. An appraisal of methods and interpretive tools is therefore necessary as well as a consideration of how theoretical concepts of maritime landscapes are finding new expressions in practice. A thematic focus is placed on integrating land and sea through case studies of maritime archaeological sites and material which range chronologically from the recent past to several thousand years before present.
\end{abstract}

J. Benjamin $(\bowtie) \cdot J$. McCarthy $\cdot$ C. Wiseman $\cdot$ S. Bevin

J. Kowlessar · J. Naumann

Flinders University, Adelaide, SA, Australia

e-mail: jonathan.benjamin@ flinders.edu.au;

john.mccarthy@flinders.edu.au; chelsea.wiseman@flinders.edu.au;

shane.bevin@flinders.edu.au; jarrad.kowlessar@flinders.edu.au;

john.naumann@flinders.edu.au

P. M. Astrup

Moesgaard Museum, Aarhus, Denmark

e-mail:pma@moesgaardmuseum.dk

J. Hacker

Flinders University, Adelaide, SA, Australia

Airborne Research Australia (ARA), Parafield, SA, Australia e-mail: jmh@flinders.edu.au; jorg.hacker@ airborneresearch.org.au
Keywords

Underwater archaeology $\cdot$ Aerial archaeology $\cdot$ Digital archaeology $\cdot$ Maritime cultural landscapes .

Archaeological theory

\subsection{Introduction}

The discipline of archaeology is currently undergoing a stepchange in site recording methods and techniques that have improved and enhanced scientific archaeological survey, excavation and interpretation. This can be described as a shift from a reliance on separate technologies in parallel to the use of converged and integrated technologies and a shift from 2D methods to 3D methods. This trend was identified by Wheatly and Gillings $(2002,216-217)$ at an early stage and examples include engagement with the technology and analytical techniques (Spring and Peters 2014), theory (Garstki 2017), public engagement (Tait et al. 2015), illustration (Morgan and Wright 2018) and archiving (Austin et al. 2009). While it is now widely recognised that photogrammetry supplements and enhances, rather than replaces, existing techniques, it has nevertheless drawn digital 3D recording firmly into the mainstream of archaeological practice. Furthermore, it has arguably pushed spatial recording through a watershed such that the gaps between pre-existing survey technologies, usually separate, have begun to be bridged. While maritime archaeology projects have employed a wide array of survey techniques, dissemination has typically been presented sequentially in archaeological reports, or perhaps overlaid in a $2 \mathrm{D}$ format. As software packages increase their capabilities, they increasingly overlap. Coupled with a general rise in computing power, archaeologists increasingly find that high resolution 3D survey datasets from separate sources can be spatially combined without having to flatten them into $2 \mathrm{D}$ beforehand.

The drivers behind a spatial approach to archaeological research include a wide array of software and hardware 
developments. Perhaps the two most important factors are the near universal adoption of multi-image photogrammetric techniques and of unmanned aerial vehicles (UAVs) by archaeologists, with both technologies enhancing each other (Colomina and Molina 2014). The dramatic rise in the application of photogrammetry for archaeology generally (Doneus et al. 2011; McCarthy 2014; Remondino 2011) has been facilitated by recent advances in software algorithms that allow semi-automated 3D reconstruction, which is a technology that is equally applicable to land, intertidal and, with a somewhat higher degree of technical preparation, underwater sites (McCarthy and Benjamin 2014). As a result, a much larger proportion of archaeologists have begun to develop 3D modelling software skills to make the most of the recording process. The desire to fully exploit these photogrammetric datasets naturally draws researchers to attempt to bring in other spatial datasets and to attempt a synthesis of 3D information within a fully 3D analytical environment. To some extent, this process of 3D data integration in archaeology has been underway for some time, most notably through the advent of laser scanning. However, photogrammetry has moved beyond the realm of the specialist into the skillsets of the maritime archaeology generalist as it is much more easily accessible and versatile, without requiring comparatively complex hardware. At the time of writing, it is likely that the vast majority of underwater archaeological divers will have been exposed to the technique at some point. This is a dramatic change from just five years ago when only very few would have heard of the technique. At the same time, the rising ubiquity of drones or UAVs has also facilitated capture of data for 3D models of entire landscapes on spatial scales accessible to such aerial platforms. This is discussed in more detail below, but regardless of which driver, it is clear that maritime archaeologists are increasingly reliant on singleenvironment multi-source spatial workflows. These lead to greater contextualization of the maritime archaeological resource. In particular, photogrammetry, which can operate at a variety of scales from the smallest artefact to the various larger scales that can be defined as a 'landscape' (e.g. local, area, regional, etc.), lends itself to a multi-scalar survey approach (Olson et al. 2013).

Alongside these benefits, the changing practice in maritime archaeology means that theoretical issues surrounding use of digital technologies must be considered. In the broader discussions of archaeology, these discussions are well underway. Huggett et al. $(2018,44)$ describe the 'grand challenges' facing digital archaeology as 'fundamental (addressing theory and practice); innovative (not simply adopting concepts and techniques from other fields); revolutionary (potential for paradigm change, creating new technological competencies and ways of knowing); inspiring (engaging across the sector and beyond); measurable (with intermediate goals to gauge progress and achievement, at the same time allowing for the possibility of failure); and co-operative (involving more than just an individual researcher or team, and crossing national and potentially disciplinary boundaries).' Huggett et al. also point out that advances in digital archaeology are not about the development of technologies by archaeologists per se, but rather, how archaeologists decide to adopt and apply digital technologies and the resulting impacts on the field.

With these concepts in mind, this chapter will review and discuss how 3D technology is changing the way maritime archaeologists work. We examine how boundaries between archaeology and environments are blurred and interpreted through emerging technology and how this allows theoretical concepts in maritime archaeology to find practical expression, specifically the concept of the Maritime Cultural Landscape (Westerdahl 1992). The wider theoretical reconsideration includes a focus on spatial relationships of material cultural within a landscape. The case studies included were chosen to illustrate the wide-ranging impacts of digital workflows across temporal and national boundaries in an integrated field of maritime and underwater archaeology. The chapter discusses methods, equipment and results of case studies illustrating contemporary practice, before reviewing the current state-of-the art in digital maritime archaeology. Emphasis is placed on the data and analyses that allow for the integration of land and sea, which make up the 'seamless' cultural landscape. Case studies range chronologically from historical periods to those sites originally formed several millennia before present. Special attention is paid to the integration of data obtained from aerial and underwater methods as these two sub-specialisations within archaeological recording are not often combined, with research groups most frequently publishing output in distinct specialist publications (with some notable exceptions, e.g. Firth 2011). This chapter will show how this gap can be bridged, integrating the aerial and underwater datasets through increasingly complex case studies that range from a simple intertidal survey, to a fully integrated maritime landscape above and below the waterline.

\subsection{Maritime Archaeological Theory and Integrated Cultural Landscapes}

Westerdahl $(1992,5)$ first introduced the concept of Maritime Cultural Landscapes (MCL) in his seminal article and explained that 'during the maritime archaeological survey... the need arose for a scientific term for the unity of remnants of maritime culture on land as well as underwater.' In the ensuing three decades after Westerdahl's influential 1992 paper the concept has become 'a dominant research area within North European maritime archaeology' (Tuddenham 2010, 6). The theoretical reaches have expanded beyond 
Northern Europe, entering the global discussion. Westerdahl himself describes the maritime cultural landscape as a physical and cognitive place 'where the boats were built, the materials, the area where the wood was taken, and finally the vessel itself and its parts' (Westerdahl 2008, 19). This eventually expanded to include an all-encompassing conceptual definition of 'maritimity', not only in landscape but in the more conceptual 'mindscape.' This idea was welcomed at the time and provided a new theoretical framework in a discipline where such frameworks were in short supply. As a result, Flatman $(2011,311)$ states that 'archaeology has witnessed an unprecedented and consistent array of work either directly on or indirectly contributing to this field of analysis by both "terrestrial" and "maritime" archaeologists.' The theory remains in fashion and appears in the title of numerous recent books and articles by maritime archaeologists (Delgado et al. 2016; Ford 2018a; Harris 2017).

Despite this ongoing popularity, difficulties in the way MCL theory is applied are apparent. Stewart (2011, vii) felt it necessary to say of MCL theory that, "we are still at an early stage, feeling our way through, but unsure of exactly how to go about it, or what we hope to accomplish.' Likewise, Ford $(2018 b, 198)$ states 'MCL supports varying perspectives. Multiple theoretical perspectives can be pursued under the MCL aegis; cultural ecology to phenomenology and Marxism to practice theory can all be explored within an MCL framework. Importantly, MCL also takes in a management perspective, allowing us to organize and manage cultural resources. It is a broad church.' The definitions of the term are certainly broad, and this has created unintended consequences that are arguably to the detriment of maritime archaeology. While increasing in breadth, without a stronger definition, its value as a concept has eroded over time. This is because the body of discussion of MCL exists as a spectrum, nebulous and expanding like its own universe, born from Westerdahl's original survey of the Swedish coasts in the 1980s. The reason may be, as Flatman (2011, 326-327) notes, that the theory is attractive to students and to researchers because it is grounded in the tangible physical world. The type of spatial relationships at the core of MCL make it one of the more accessible theoretical frameworks with which most people can identify, even for newcomers to maritime archaeological theory. Unfortunately, the very accessibility and the openness of MCL to different interpretations has, over time, led to an increasing vagueness of definition and lack of theoretical direction.

Those who have sought to apply the theory in a practical Cultural Heritage Management context, have run into very difficult to answer questions, not least of which is how far from the shore we should consider an MCL to extend (Ford 2018b, 199-201) and what is and what is not 'maritime' within the anthropological or archaeological discourse (see Gately and Benjamin 2018). Many of the publications refer- encing the theory, even as part of their title, are little more than catalogues of the maritime culture and history of a region rather than attempts to develop the theory into something more complex or to explore cognitive relationships with material culture past and present, as well as the more prosaic physical environment aspects. This is perhaps because maritime archaeologists are generally conscious of the need to engage with archaeological theory and have tended to rely on MCL as a convenient seat filler which does not interfere with the scope of their particular study. After all there is probably no archaeological site to which MCL theory could not be applied in some form. The use of MCL in this way contributes little to the broader discipline, which is already overly techno-particularist and sorely needs longterm and genuine engagement with well-defined, useful, theory. In some cases, MCL has been treated as though it were a concept which could be tested to see if it existed in a given area, but as Rönnby (2007, 80-81) notes, 'the challenge is probably not so much to prove that a special environment plays a role in the formation of societies and cultures. It is evident that it does.'

If technology itself is neutral, can technological advancements be used to focus the development of archaeological theory? In an appraisal of the state of MCL studies just prior to the boom in photogrammetry algorithms that have so greatly impacted archaeology, Stewart (2011) identified two major challenges for the future of MCL studies. Firstly, he notes the need to bring cultural interpretation into maritime landscape surveys. Secondly, he notes the technical challenges of past landscape reconstruction. In the case of the first challenge, as we have noted above, MCL theory has been attractive and accessible due to its spatial nature but this has been to a large extent a subjective mental exercise. As a result, so plentiful are the interpretative possibilities for a past maritime landscape, that the collective body of research has been unable to make much progress. Choices are made by the archaeologists on which sites to focus within a landscape and at which scale they are to be surveyed. This is often invisible in the final products. For the second challenge, Stewart states that landscape reconstruction 'requires geographical, geological, or geoarchaeological experts, but the specialists in these fields do not generally have expertise in maritime culture. By the same token, specialists in maritime life-nautical archaeologists, maritime historians, and maritime ethnologists - do not typically have expertise in reconstructing landscapes' (Stewart 2011, viii). In the years since these two challenges were identified by Stewart, the rise of much more user-friendly software and the relative ubiquity of powerful hardware means that maritime archaeological practitioners and even maritime archaeology students may have at least basic skills of landscape reconstruction within their grasp. In many cases discussions of MCL have been bound by a lack of materiality but new technologies 
allowing comprehensive landscape and seascape survey increasingly allows for a practical implementation of MCL theory in praxis.

These emerging techniques offer a higher level of detail than previously available to most field archaeologists. Rather, there is a newfound, and reasonably accessible means for many archaeologists to capture data to reconstruct a physical landscape digitally and in 3D. This provides a previously unattainable baseline for developing and testing theories related to landscape-material-culture interconnection and context, spatial relationship and setting which leads to the broader opportunities to review more anthropological questions as related to cognitive and social significance. We consider the MCL as a social construct based on cumulative characteristics of the physical environment and all of the natural resources and challenges they offer to societies past and present. Rönnby's point is worth heeding: (2007, 81): 'The challenge is instead to show how people within a very special maritime milieu and linked to 'maritime durees' within these surroundings have nevertheless constructed their social situation so differently...' While mapping in 3D alone might not resolve these issues, the added value of these outputs provides a newfound baseline to study maritime cultures. The physical environment impacts the cognitive landscape and must be considered, along with archaeological material, as a starting point, with consideration for change over time. A review of physical landscape over time begins with a data-driven exercise of material culture to interpret and understand the physical environment, exploited and culturally modified by past cultures. The development of technological approaches allows for a deliberate re-emphasis on the material as a data source, evaluated in detail and spatially, in a physical and virtual space.

One of the greatest advantages of a 3D survey-driven approach for maritime archaeology is the potential to digitally 'dissolve' the boundary between terrestrial and underwater environments. The modern coastline gives the archaeologist in the field a misleading impression of the contemporary physical landscape of an archaeological site, obscuring and distorting the lost landscapes of the past. In his introduction of MCL, Westerdahl (1992:6) recognised the importance of a survey strategy that spanned from land to sea so that 'a vision of the total topography of the waterfront area is applied, features on nearby land being as important as depth curves underwater.' Only through a survey strategy that seeks to capture the topography across the modern land, intertidal and submerged, can we achieve an informed approximation of the contemporary landscape context of the site and therefore study the cultural relationship between past people, materiality, land and sea. Considering as examples two of the most widely studied types of maritime archaeological sites, shipwrecks and submerged prehistoric sites, Westerdahl's statement is certainly true for submerged prehistoric sites. For shipwrecks, Westerdahl recognised that they could be challenging to include in the maritime land- scape concept as they lacked, 'at first sight any obvious relationship to their immediate surroundings' (Westerdahl 1992: 6) but there are many links, including the relationship between the coastal topography and the wrecking event, post-wrecking site formation processes and interactions between the wreck and onshore communities from the time of wrecking onwards. For this reason, the comprehensive 3D survey approach has the potential to be equally relevant to all maritime archaeological sites.

\subsection{Aerial Archaeology}

Airborne observation and recording techniques for archaeology have been practiced for several decades and are discussed in technical breadth and depth in various publications (e.g. Bewley and Raczzowski 2002; Cowley 2011; Cowley et al. 2018; Duel 1969; Riley 1982). While the work undertaken from the air during the earlier twentieth century focused primarily on oblique photography or on vertical orthographic stereophotography, recently the focus has shifted to photogrammetry capable of dense 3D capture of land surfaces (e.g., Remondino 2011). This has also been true of coastal maritime archaeology (e.g., Benjamin et al. 2014; Cowley et al. 2012). Beyond photogrammetry, Lidar has also grown in popularity thanks to wider availability of data and more powerful computers. Bathymetric Lidar has also had an impact on coastal and shallow water archaeology (e.g., Doneus et al. 2013) and there have been studies exploiting publicly available bathymetric Lidar data for palaeolandscape reconstruction (Bicket et al. 2017). These methods for aerial recording have so far focused on 'manned' aircraft using traditional survey and data processing and interpretation methods.

Data acquisition at a local scale or site scale has been increasingly acquired by UAV. This popularity of UAV-based technologies prompted the dedication of a special issue of the Society for American Archaeology's newsletter (SAA 2016) to showcase the potential for archaeological sites and landscapes to be recorded by UAV. Here, we consider a shift in most photographic data from manned aircraft to UAVs. The advent of the small, consumer grade UAV means that any archaeological unit, department individual researcher or student can now take low altitude aerial photographs in a small scale, affordable manner. This latter point is perhaps the single greatest step-change for mapping sites located on dry land, since more sites and landscapes are now easily documented from above, which otherwise would not have been recorded in this way. We are nonetheless careful not to mistake this increase in the deployment of UAVs as an outright replacement for other methods. In terms of manned aircraft, there are now solutions available based on modern comparatively lowcost small motorglider and/or ultralight aircraft equipped with multitudes of sensors, including the most powerful full waveform-resolving small footprint lidar systems, high resolution 
cameras and more (Hacker et al. 2018a, b). Combined with new survey strategies and processing workflows, such solutions are delivering very detailed data for landscapes on local $(\sim 1 \mathrm{~km})$ to regional scales (i.e. up to hundreds of kilometres). This is especially useful if larger datasets are employed for context, and particularly where the broader geomorphological context is relevant. Consequently, the needs of any given survey, and not a pre-determined choice of aerial technologies, should dictate the right tool for the job (Fig. 14.1) (Neininger and Hacker 2011; Cowley et al. 2018). This is evident in the
Fig. 14.1 Historic building recording through photogrammetry (Taken from the air. (Ardtornish Castle, Scotland). Figure contains Ordnance Survey OpenData, Crown Copyright 2018)
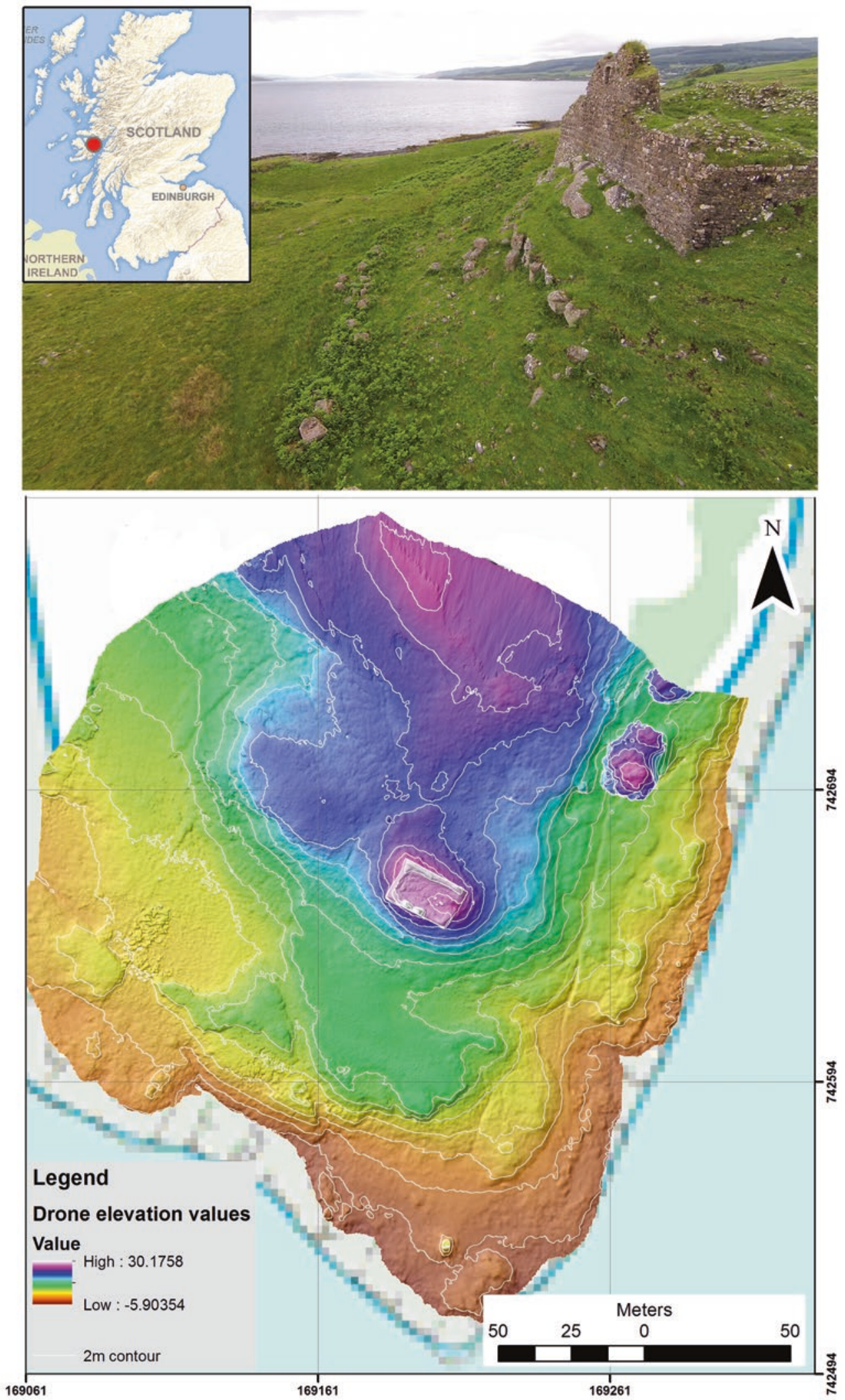
case studies presented herein which rely on data collected through a combination of UAVs and manned aircraft as both have their own strengths and weaknesses and their own place in coastal and marine landscape survey.

The availability of consumer-grade UAVs within the last decade allowed for the widespread adoption of aerial photography roughly in parallel with the advances in underwater digital photography, both of which provided raw data to feed into the newly available consumer-grade photogrammetry pipelines. Most notable in the low-cost range of UAV are those developed by Chinese UAV company DJI (with over $70 \%$ of the global market share as of 2017) (Chen and Lynch Ogan 2017, 57). Use of both multi-rotor and fixed wing UAVs (Remondino et al. 2011) have added to the suite of methods and tools for aerial recording. In many situations, drones have replaced the diverse and traditionally comparatively costly array of aerial photography techniques previously in use by archaeologists. Cowley et al. (2018) remind, however, that this is not necessarily true for all situations and the method of aerial survey should always be decided by the archaeological purpose. A typical example may be a study requiring identification and initial mapping of remote and/or larger areas not easily accessible to UAV-based surveys where the above mentioned small manned aircraft have considerable advantages, even in terms cost-efficiency. There are also a multitude of other methods on offer, the cost of which has to be carefully analysed, such as scaffolding towers, extendable photo poles, kites and balloons which can be combined with photogrammetry.

\subsection{Technical Challenges: Shallow Water and Intertidal Zones}

Working within the intertidal zone has always been a challenge for maritime archaeologists for both excavation and remote sensing survey. While sonar techniques have been the mainstay of marine remote sensing survey and aerial lidar or image-based techniques have been foremost terrestrially, the difficulty of applying remote sensing techniques to the shallow and intertidal zone resulted in the so-called 'white ribbon', a zone extending from the minimum depths for sonar and geophysical survey up to the coastline (Kotilainen and Kaskela 2017).

The recent rise in sophisticated photogrammetry algorithms, commonly available software, combined with the increase in computer processing power have had a strong impact on coastal and shallow water archaeology (e.g. Kreij et al. 2018; McCarthy and Benjamin 2018). Recording for 3D has become an important part of the maritime archaeological process, both technically and experientially, as 3D recording has the potential to bridge the gap between terres- trial and underwater archaeology. In this respect photogrammetry is similar to bathymetric lidar (Bicket et al. 2017; Doneus et al. 2013; Kotilainen and Kaskela 2017) although the latter technique has impacted the discipline less due to a much higher relative cost. Underwater photogrammetry, where the camera is submerged, is difficult in shallower environments, due both to the increased effect of caustics and to the forced proximity of the camera to its subject. The effect of caustics can be reduced to some extent by waiting for diffuse natural lighting due to oblique sunlight or cloud cover. For distance, the surveyor can use a very wide-angle lens with a very tight line spacing. One solution can be applied in areas with a large tidal range, where surveyors can increase the distance between camera and subject by waiting for high tide. The same approach can be used for fully intertidal sites, where terrestrial survey techniques can be applied at low tide while underwater techniques may be applied to the same location at high tide.

There have been a number of studies that have addressed the technical challenges of aerial air-to-water photogrammetry, sometimes referred to as photo bathymetry (Maas 2015, 18141). A growing number of studies that have reviewed methods for overcoming issues, including sun glitter (Mount 2005), refraction (Georgopoulos and Agrafiotis 2012) and wave-related distortion (Chirayath and Earle 2016). As with underwater photogrammetry, the value of shallow water survey is strongly correlated to water clarity, but it is also particularly limited by factors which are either absent from terrestrial and fully underwater photogrammetry or which have a much less-pronounced effect on the quality of results. These factors include the Fresnel reflection of water and glitter from sunshine as well as ray distortion caused by both wave action and by refraction of light as it passes from air into water. The effects of these factors can be limited by taking aerial photographs as near to vertical as possible to both reduce the effects of refraction and constrain the remaining refractive distortion to radial, use of circular polarising filters to cut down reflections and by shooting when the water surface is as calm as possible. This is the approach taken in the case studies presented below. In ideal conditions for coastal photography by UAV for photogrammetry, it is possible to capture 3D surfaces through the water for the first few metres, such that shallow bathymetry and features are expressed in the resulting 3D models. Finally, it is worth noting an interesting recent study which has combined under and above-water scans of floating vessels (Menna et al. 2015), dissolving this barrier in a similar way through a different method.

Considerable new developments have also taken place for using bathymetric lidar in the intertidal and shallow water zone, down to about $12 \mathrm{~m}$ water depth. This involves two 
full-size small footprint waveform-resolving lidars on an above-mentioned small traditional aircraft flown in innovative multi-overpass flight patterns together with sophisticated data processing and interpretation workflows (Hacker and Pfennigbauer 2017).

\subsection{Underwater Photogrammetry}

The various chapters found throughout this volume illustrate the widespread and ubiquitous nature of underwater photogrammetry, and how it has revolutionised maritime archaeology in a short period. The development of these technologies has generally not been driven by maritime archaeologists and has a much larger literature in technical publications from various disciplines. However, the adoption of the technology by maritime archaeologists as it developed is of direct relevance. Contemporary to some of the early work in aerial archaeology, photogrammetric methods in underwater archaeological site recording were implemented as early as the 1960s (Bass 1966). The subsequent decades saw incremental advancement in the adaptation of photogrammetric 3D recording for underwater archaeology, with pioneers (see Drap et al. 2003; Green and Gainsford 2003) pushing the boundaries of available software. From 2006 onward, publications appeared utilising multi-image photogrammetry for small archaeological objects underwater using highly technical workflows. Henderson et al. (2013) marked a step-change in photogrammetric site recording under water by analysing much larger numbers of images on a site-level scale by Autonomous Underwater Vehicle (AUV), in the shallow waters of Greece. Up to this point most of the adoption of multi-image approaches had relied on expensive workflows that were not practical for the wider archaeological community. From 2013, however, this began to change. McCarthy and Benjamin (2014) demonstrated a low-cost approach that was affordable for most maritime archaeology practitioners and was also effective, at the Drumbeg historic shipwreck site in NW Scotland (see also McCarthy et al. 2015). Yamafune et al. (2016) showcased new approaches to reconstruct large wooden wrecks in 3D using photogrammetric data as a baseline. Liarokapis et al. (2017) used underwater photogrammetry to map a fourth-century shipwreck in Cyprus and to create an immersive virtual reality experience for the site. In short, since 2009, maritime archaeology has developed the ability to move beyond a half century of reliance upon manual diver recording (with some assistance from sonar techniques) for complex underwater archaeological sites to being able to capture full shipwrecks and submerged settlements within only a few dives. While this has augmented rather than replaced existing techniques, it has significantly reduced the amount of time required to record a site, which is critical when considering the constraints imposed by dive times and working under water (which can often be a small fraction of what could be achieved on land). Thus, time is of the essence for the underwater archaeologist and new technological approaches have brought in considerable savings in time, cost and risk, while at the same time providing a much richer and more objective record of the archaeological sites.

\subsection{Digital Maritime Landscapes in 3D: Case Studies}

Combining the techniques referred to in the preceding sections allows us to dissolve the line dividing land and sea. The archaeological landscape can be composed of terrestrial, intertidal and marine environments. Thus, the integration of datasets can form a 'seamless' cultural landscape in 3D. This can significantly enhance interpretation and research as well as public outreach. In the following examples, aerial data were collected by traditional aircraft as well as by remote pilot operation. Underwater data were collected through inwater photography techniques, designed for photogrammetric modelling, while snorkelling, SCUBA diving and by boat. These case studies are presented with an increasing degree of complexity, from a straightforward intertidal zone site survey to a fully integrated terrestrial, intertidal and marine digital 3D landscape. This progressive demonstration provides a gradual introduction to the applied methods. They also become more intricate with each example in an effort to demonstrate how the techniques can build upon one another with increasing complexity, integrating more and more data from different sensors.

\subsubsection{The Intertidal Zone}

Two intertidal surveys from Scotland demonstrate the effectiveness of aerial documentation undertaken in the intertidal zone. Intertidal archaeology represents the transition zone, sometimes underwater and sometimes exposed. It can be difficult to record due to the dynamic environment and constantly changing conditions. It can also be dangerous, in some cases, where tides move quickly, and surface conditions are muddy. Surveyors must take extra care, or indeed cancel a survey plan that involves too much risk. This is precisely where intertidal archaeology benefits from aerial approaches to site and landscape survey (Cowley et al. 2012).

The remains of a small wooden boat at Ardno on the shores of Loch Fyne, Scotland was found with only the lower part of the hull intact (Fig. 14.2). The wooden carvel remains were obscured under intertidal seaweed and after a full manual and photogrammetric survey of the site, further research unearthed a probable identification of the vessel and early photographs 


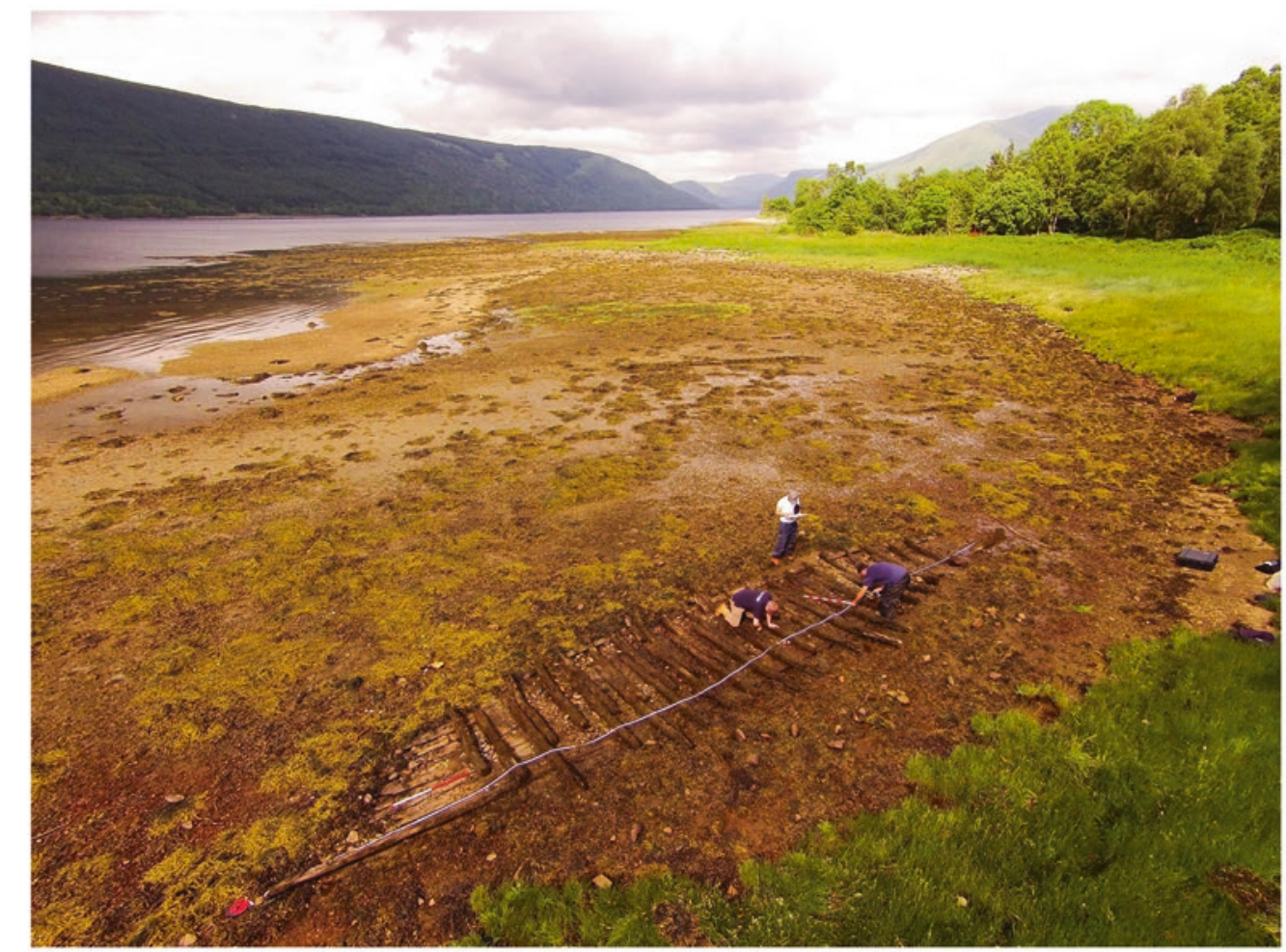

Ordnance Survey Crown Copyright 2018
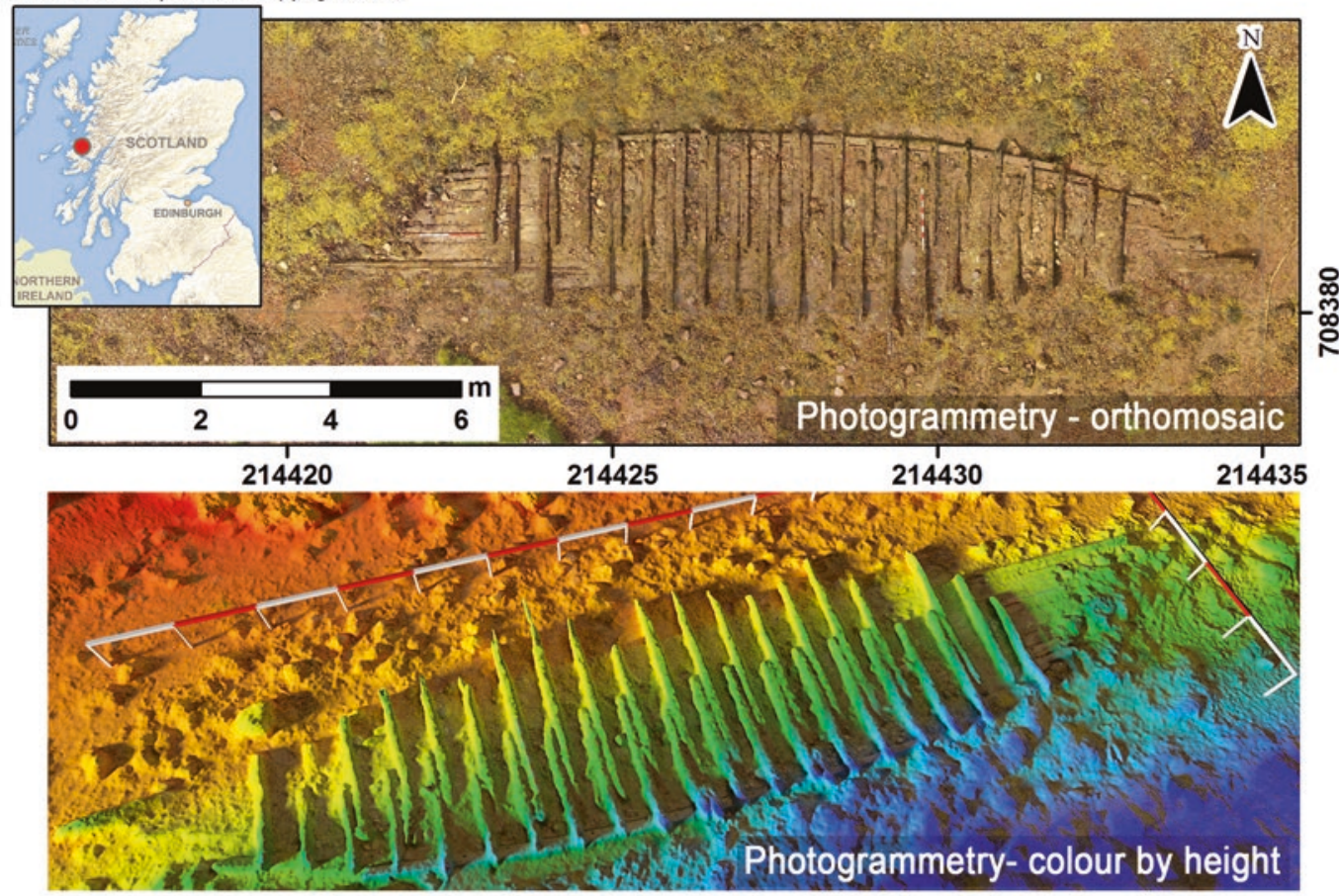

Fig. 14.2 The Ardno historic boat remains were reported to the SAMPHIRE project team (McCarthy and Benjamin 2018) and recorded through both traditional nautical archaeological techniques and aerial-based rapid recording methods

dating to around 1910 (McCarthy et al. 2015:C27-C29; McCarthy and Benjamin 2018:13-14). The Ardno hull represents a simple recording technique with a very low flying (below the tree level) UAV to record the previously unknown vessel. A DJI Phantom V2+ (v.3) was deployed with its builtin $12 \mathrm{mpxl}$ camera. The camera itself is a fisheye with 115-degree, distorted view. This can be partially corrected in software such as Adobe Lightroom (through a standard lens 
Ordnance Survey Crown Copyright 2018

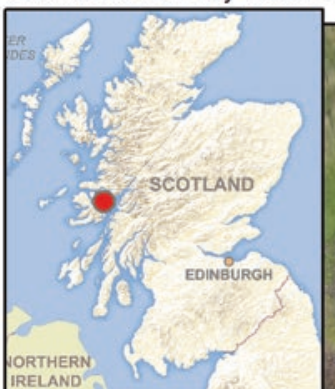

IRELAND
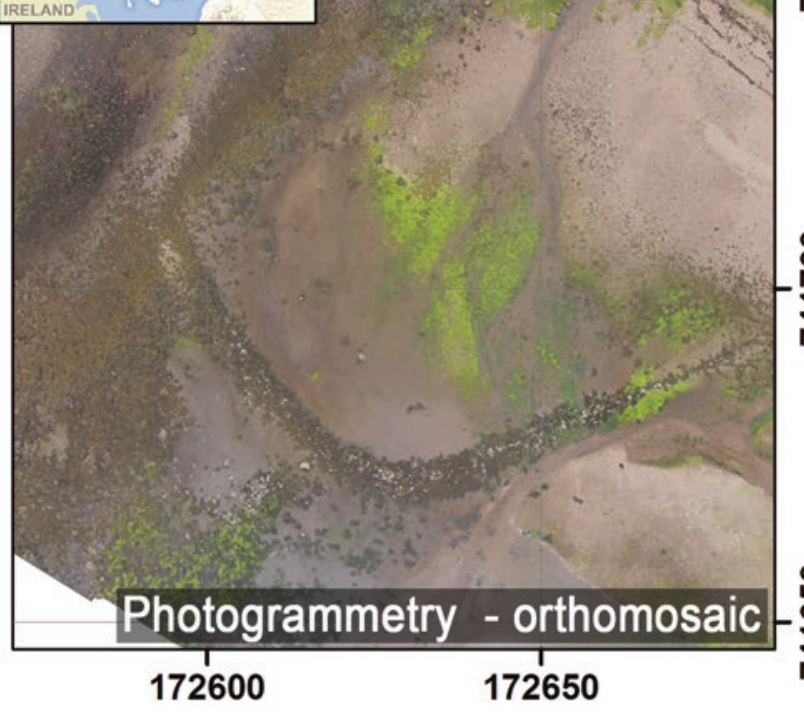

172600

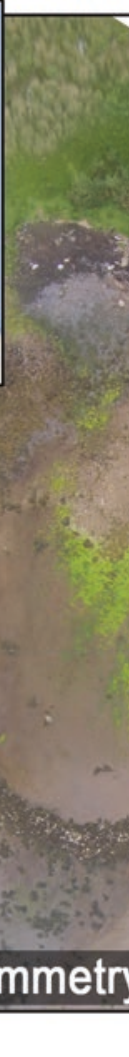

172650

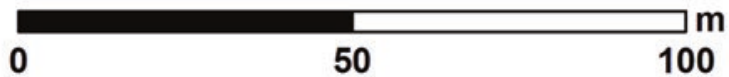

100

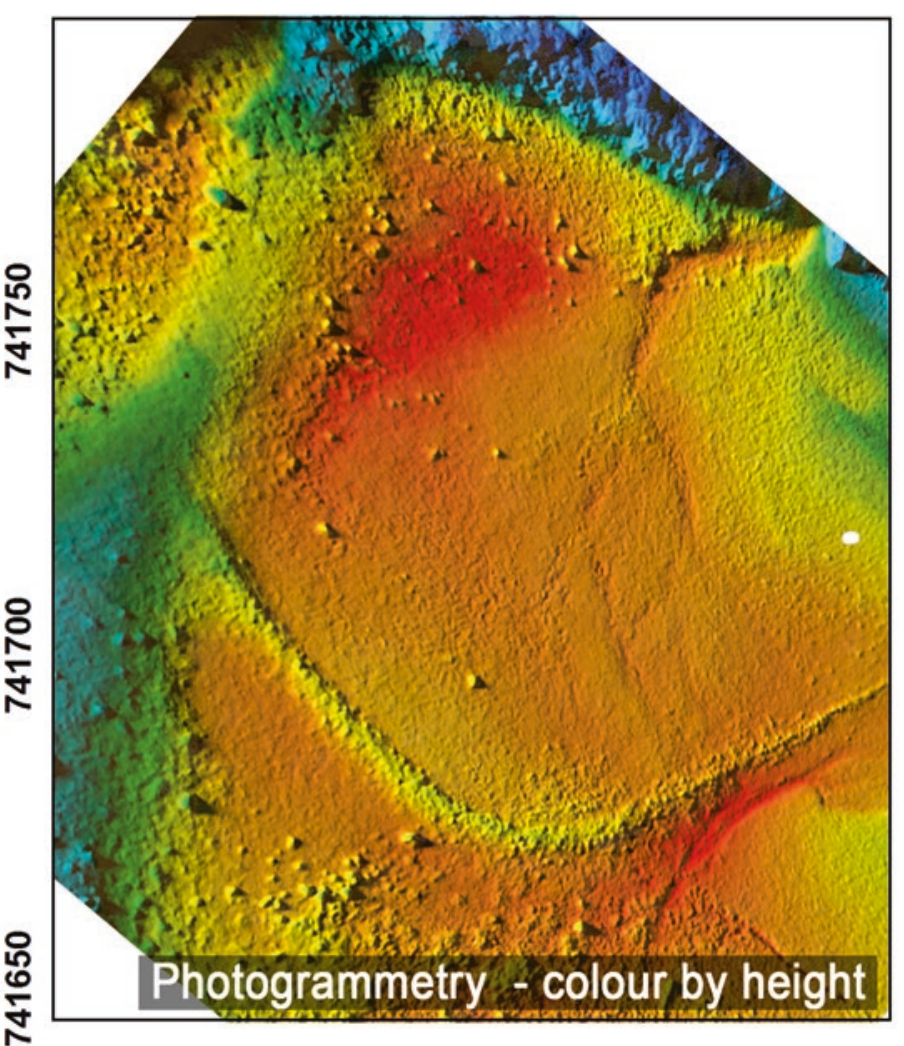

Fig. 14.3 The historic fish trap at Inninmore, sound of Mull, recorded by UAV deployed from a small boat as a platform for rapid survey of remote or inaccessible locations

profile) or, for 3D photogrammetric recording, Agisoft Photoscan/Metashape contains an algorithm that can account for the majority of the distortion through recognition of the camera in the image file metadata. The results at the Ardno survey, undertaken in less than a half hour, demonstrate use of a small, consumer-grade UAV flown at very low altitude. Both 3D and 2D images are useful to consider the site within the landscape, and for reconstructive purposes. A similar process was undertaken for the fishtrap at Inninmore, which was recorded from a UAV deployed from a vessel (Fig. 14.3). The use of a vessel-based platform for UAV operations brings another option for rapid recording of sites which are situated in locations that are otherwise difficult to access.

In contrast, two intertidal Mesolithic sites in NW Scotland are selected to demonstrate landscape-scale recording of Scotland's intertidal (or 'partially submerged') prehistory (Fig. 14.4). The lithic processing site at Lub Dub Aird (Loch Torridon) and the peat deposit at Clachan Harbour (Isle of Raasay), represent the only confirmed intertidal prehistoric sites in Scotland which have been impacted by postglacial sea-level rise (Hardy et al. 2015) though they both remained partially preserved until the time of their discovery (Bailey et al. 2019) ${ }^{1}$. At both sites, traditional aircraft (Cessna 172) and DSLR cameras were used to survey the contemporary landscape in 3D. The 3D capture of landscapes is particularly useful for interpretation of past landscapes and land surfaces where sea-level rise impacted the setting of the site itself. The lithics found at these sites represent Mesolithic deposits (Ballin et al. 2010; Hardy et al. 2015). Sea level during the Scottish Mesolithic was approximately between 3 and $15 \mathrm{~m}$ lower than today's mean sea level (MSL). This has an interpretive importance, not only for contextualising the otherwise ephemeral lithic scatters in today's landscape, but also for interpreting their geographic setting past and present.

\footnotetext{
${ }^{1}$ Recently media reports appearing just before this volume went to press have mentioned some important, but as yet unpublished, discover-
} ies at Benbecula.' 


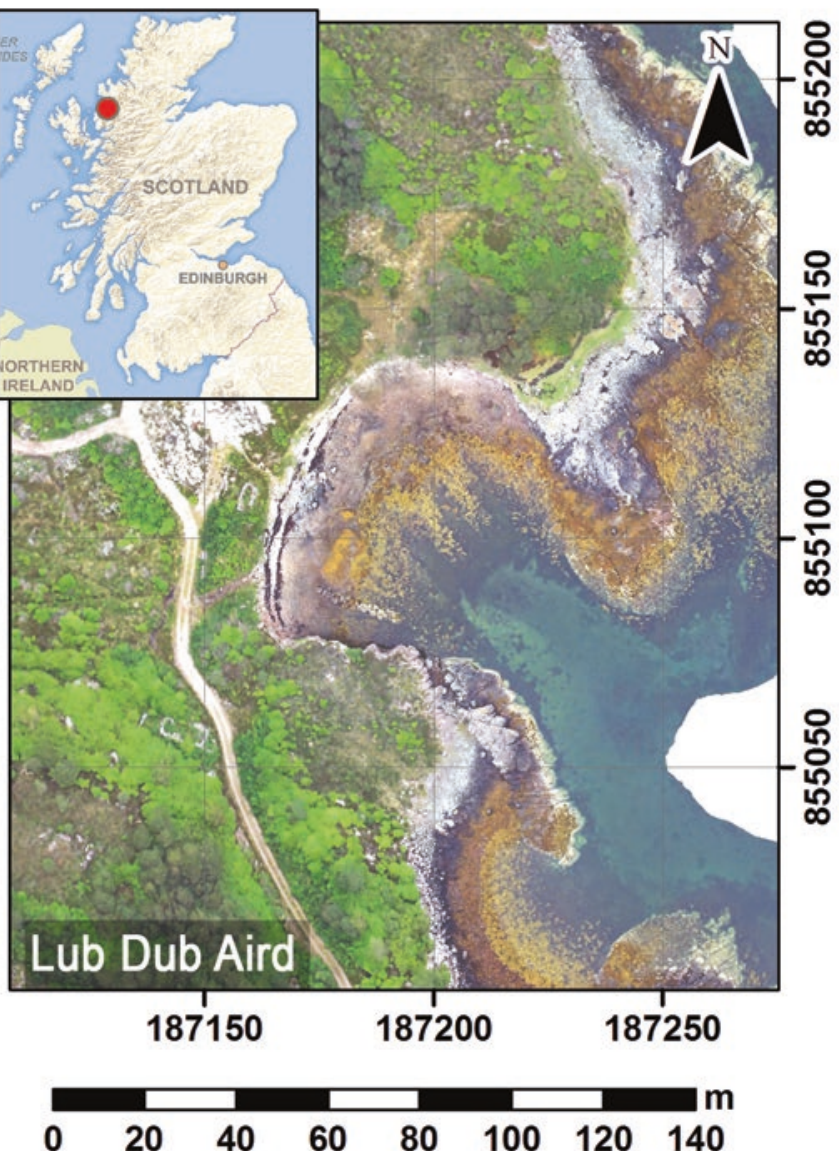

Fig. 14.4 Lub Dub Aird and Clachan Harbour landscape settings in 3D. These two locations represent the only two excavated find spots where Mesolithic deposits have been confirmed in the intertidal zone. The landscapes were recorded by traditional aircraft and camera equipment in order to capture the sites' settings. The past landscapes can be

\subsubsection{Nearshore Historic Shipwrecks}

Two historic shipwrecks in south-eastern Australia are presented as case studies. The recording of these two sites demonstrate different methods which can be used to integrate a fully underwater site within its surrounding environment. In these cases, the remains of the vessels represent historic wrecking events in the nineteenth century and the sites themselves were both partially salvaged by local inhabitants after the wrecking event took place. Star of Greece was the place of a loss of significant life, where 18 sailors perished near Port Willunga, South Australia (Ash 2007). Leven Lass wrecked in Victoria in comparable conditions, near shore on an exposed reef (Roberts et al. 2015) and both sites are protected by Australian law through The Historic Shipwrecks Act (1976).

The Star of Greece shipwreck is a well-known maritime archaeological site and tragedy in South Australia. Built in
Contains Ordnance Survey OpenData. Crown copyright 2018.

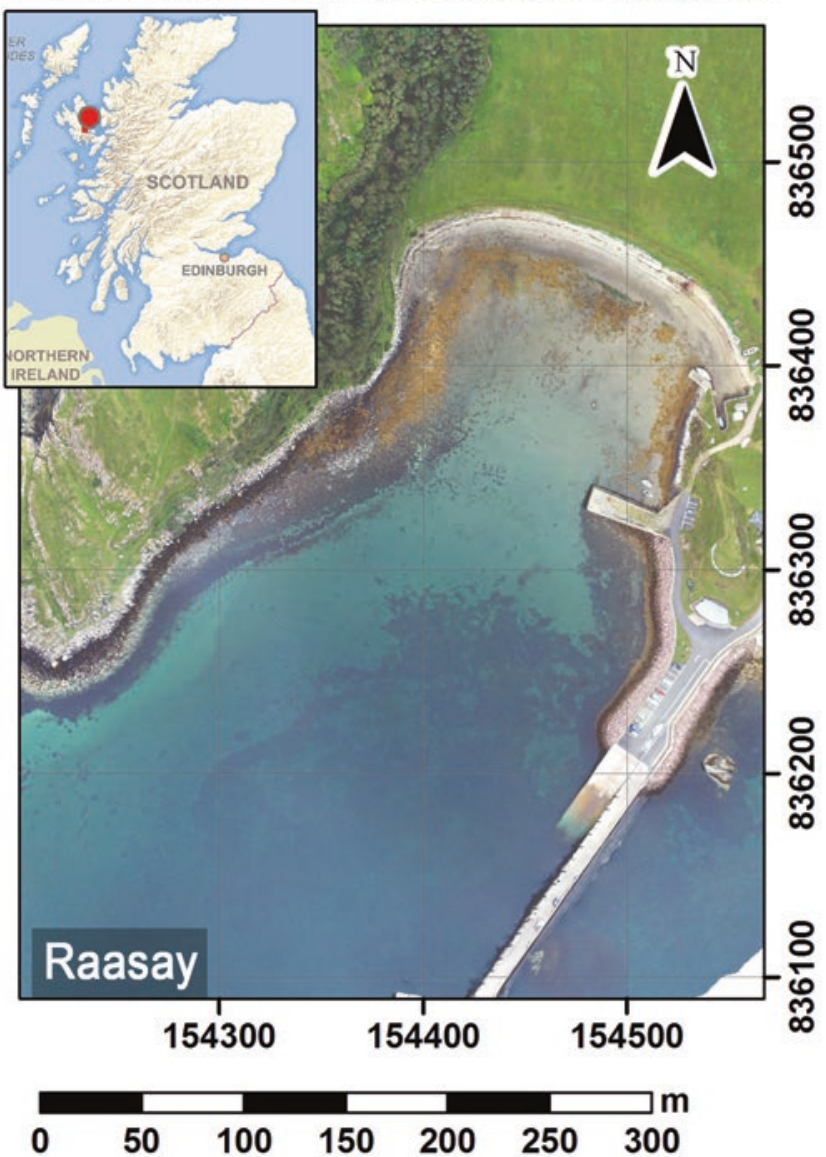

inferred by comparing sea-level models and adjusting the digital elevation accordingly, in line with the depth:age ratio of the Mesolithic period in western Scotland and taking into consideration location-scale isostatic uplift

Belfast, Northern Ireland, by shipbuilders Harland \& Wolff in 1868 , it sank in bad weather, bound from Adelaide to London in July 1888 . The site itself is approximately $2-5 \mathrm{~m}$ deep, located less than $200 \mathrm{~m}$ from shore. It was recorded by Ash (2007) requiring more than 30 dives to plan the site manually. Returning to the site in 2015 , a single aerial photographic excursion and several attempts to record the site photographically were made; the latter proved difficult due to the size of the vessel and as such a complete site plan in high-definition 3D remains to be completed. The first attempt to record the site through underwater photogrammetry was undertaken by SCUBA divers, who managed to record only $15 \%$ of the vessel in two dives, although over 2000 photos were taken. Further attempts were made to record the vessel by boat-based photogrammetric techniques in 2017 and 2018. The resulting survey established a near-complete 3D site record through data acquired by a pole-mounted housed, stereo camera system (Sony RX100 M3) (Fig. 14.5). 

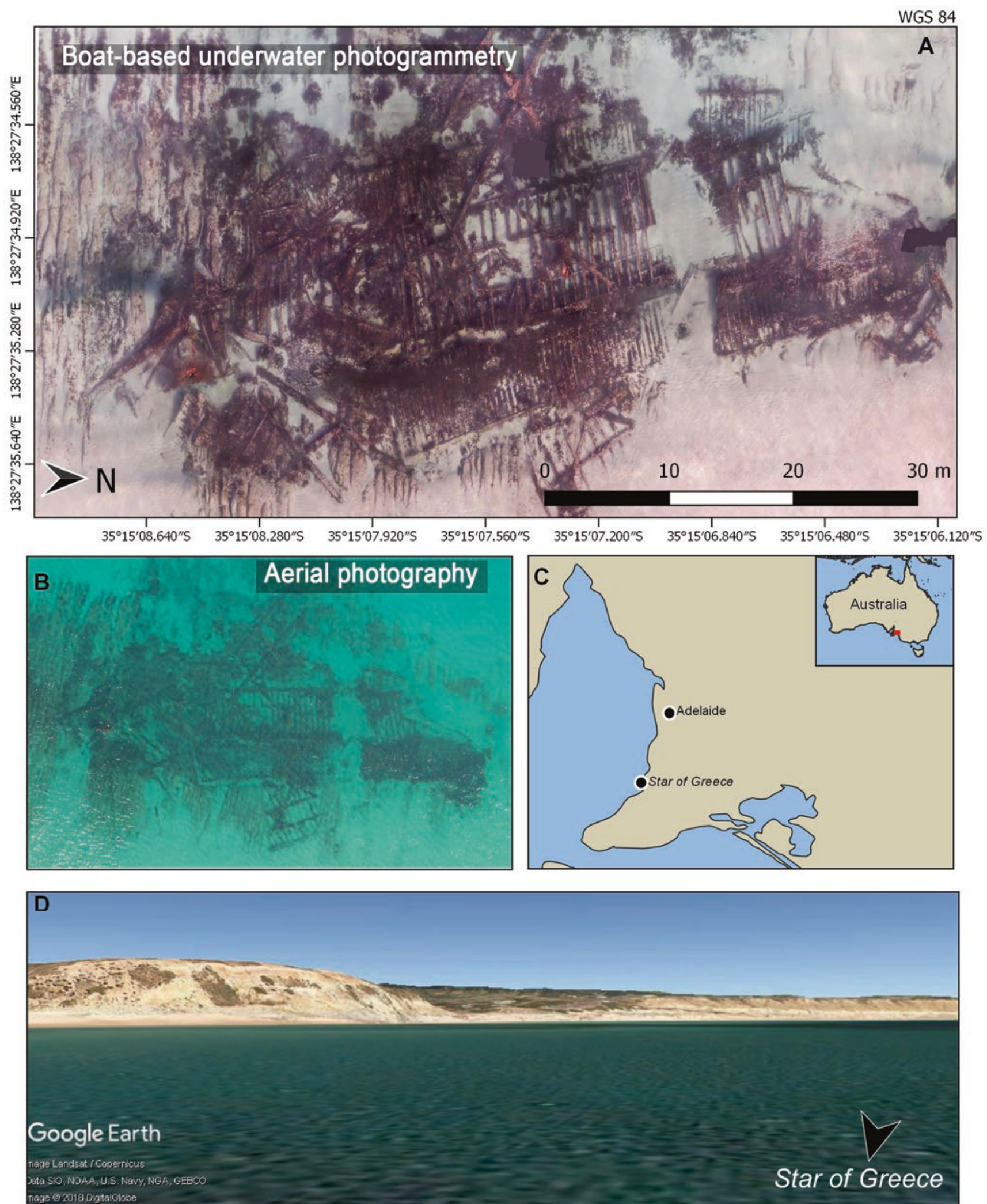

Fig. 14.5 The Star of Greece shipwreck was recorded using boatbased photogrammetry based on over 6000 images to produce a 3D record. It is shown here as a $2 \mathrm{D}$ orthophoto alongside an aerial image of the wreck site. Resources like Google Earth now provide a simple way of providing wider context of archaeological sites 

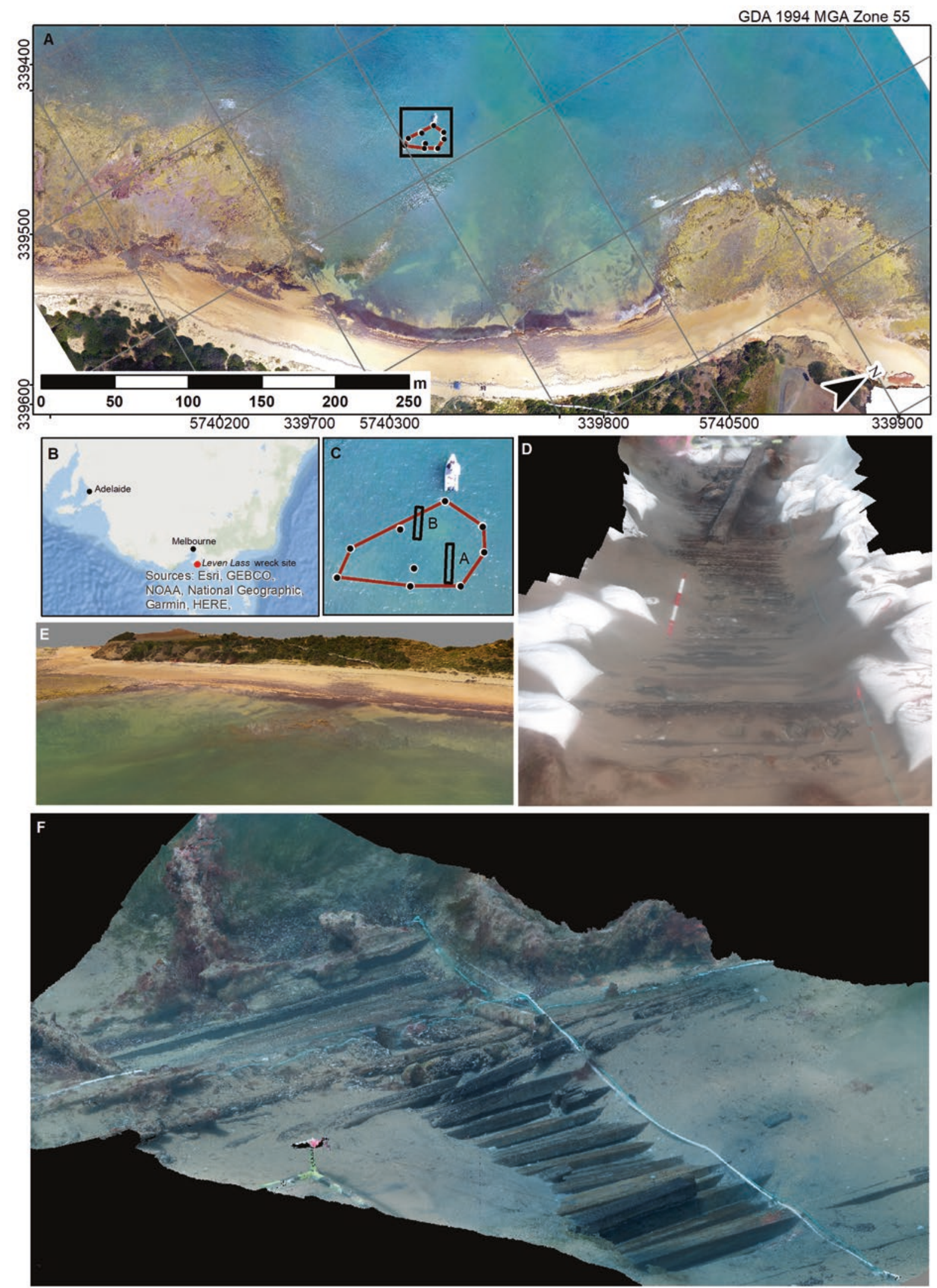

Fig. 14.6 (a) Location of Leven Lass, overlaid on aerial photogrammetry, showing landscape context; (b) Orientation map showing the location of the Leven Lass wreck site; (c) Leven Lass wreck site including survey points and trench locations; (d) Oblique view of photogram- metric survey of Trench A, looking northwest; (e) Oblique view of photogrammetric survey of Little Rookery Beach landscape, looking east; (f) Oblique view of photogrammetric survey of Trench B, looking southeast 
In 1984, the remains of an unidentified wooden vessel were recorded by Heritage Victoria in approximately $4 \mathrm{~m}$ of water off the northern coast of Phillip Island, Australia. Flinders University-Heritage Victoria field investigations from 2012 to 2017 identified the shipwreck site as the nineteenth-century Clyde-built (Scottish) brig, Leven Lass. The site is used as a teaching location, where graduate students have been able to learn shallow-water 2D and 3D recording methods. In addition to underwater photogrammetric recording by simple housed compact camera (Fig. 14.6), aerial based photogrammetric data were acquired by UAV (DJI Phantom 2V+) at this site. The integration of the aerial and underwater data showcases the shipwreck, in its landscape context and with visible reef in immediate proximity. The vessel itself remains reasonably well-preserved, despite several early attempts to salvage the site followed by decades of artefact removal by local snorkelers and divers. A 2D orthophoto was produced to compare alongside student drawings of Trench A, excavated in 2015 (Fig. 14.6d), and Trench B excavated in 2016 (Fig. 14.6e).

\subsubsection{Deep Time and the Integrated Maritime Landscape}

The case studies illustrate the recent and rapid integration of digital 3D recording techniques. They demonstrate the sitescale, showcasing three historic (post-medieval or postcontact) sites and two local-scale archaeological landscapes of intertidal Mesolithic sites in Scotland and provide varying levels of data integration and archaeological setting. Here we reiterate that the spatial data and interpretation of 3D data differ when considering drowned palaeolandscapes and the cultural deposits therein/thereon. Historic shipwreck sites may be studied for their relationship with the surrounding terrain in which they sank, or ruined in a final punctuated event, however their origin (construction place) is not often their final resting place. This differs from the prehistoric sites inundated during postglacial sea-level rise. A submerged settlement provides an opportunity to apply digital techniques, to study site formation, preservation processes and, in a practical sense, future management. 3D data is particularly useful for underwater cultural heritage of drowned landscapes, within modern shorelines, intertidal zones and coastal (terrestrial) environments because the water level represents a somewhat arbitrary segregation that historically introduced research bias and certainly presents a modern, technical challenge.

The coastline of Denmark is surely one of the best places in the world to study impacts of climate change and sea-level rise on past peoples (e.g. Fischer 1995; Uldum et al. 2017).
A Mesolithic site located on the island Hjarnø (Astrup et al. 2019; Skriver et al. 2017) represents an outstanding opportunity to integrate multi-scalar $3 \mathrm{D}$ recording techniques and present a complex site in high resolution. This is important because submerged material from Denmark has been recorded for several decades using traditional archaeological recording methods. However, the dissemination of the research has suffered historically from a lack of detail due to generalised illustrations and poor-quality underwater photography. The ability to recreate a landscape from aerial and underwater means has led to a high quality, scalable, photorealistic resource that is more informative and therefore of higher value to international scholarship and museum visitors alike.

The landscape of Hjarn $\varnothing$ (Figs. 14.7 and 14.8) was analysed using a terrestrial Lidar dataset with a resolution of $0.4 \mathrm{~m}$, alongside a bathymetry dataset with a resolution of $50 \mathrm{~m}$ (interpolated data based on one point per $50 \mathrm{~m}$ ). Both datasets are readily available to the public. Given the substantial variation in resolution between the two datasets, GIS-based interpolation allowed for the combination of the bathymetry and topography. The bathymetry and topography datasets were merged into a singular data layer, which was then interpolated to a DEM using the kriging method at a resolution of $5 \mathrm{~m}$. Contour lines of $5 \mathrm{~m}$ were generated from the elevation model to be used in the creation of a TIN surface to then visualise this region in $3 \mathrm{D}$. A variety of photogrammetric surveys were then made of the areas of archaeological interest, including UAV photography for photogrammetry of the terrestrial and intertidal areas undertaken at low tide, underwater snorkel and diver-based photogrammetric survey of excavated trenches and artefacts, surface photogrammetry of the entire seabed around the midden. These datasets were then merged into a single 3D environment in GIS and in the 3D modelling software Blender, with floating surveys georeferenced using the total station dGPS survey. Further work is ongoing to integrate the results of coring and excavation both at the site itself and in the wider landscape (Astrup et al. 2019).

\subsection{D GIS}

Geographic Information Systems handle complex spatial information however this information is typically represented in a simple 2D format with 3D data and offer archaeologists a platform and collection of tools with which to manage complex spatial data sets. Despite a visual disconnect between the data and reality these types of displays have been widely accepted and utilized by archaeologists. While commercial 3D GIS packages have existed for some time, these are typically expensive products and designed for spe- 

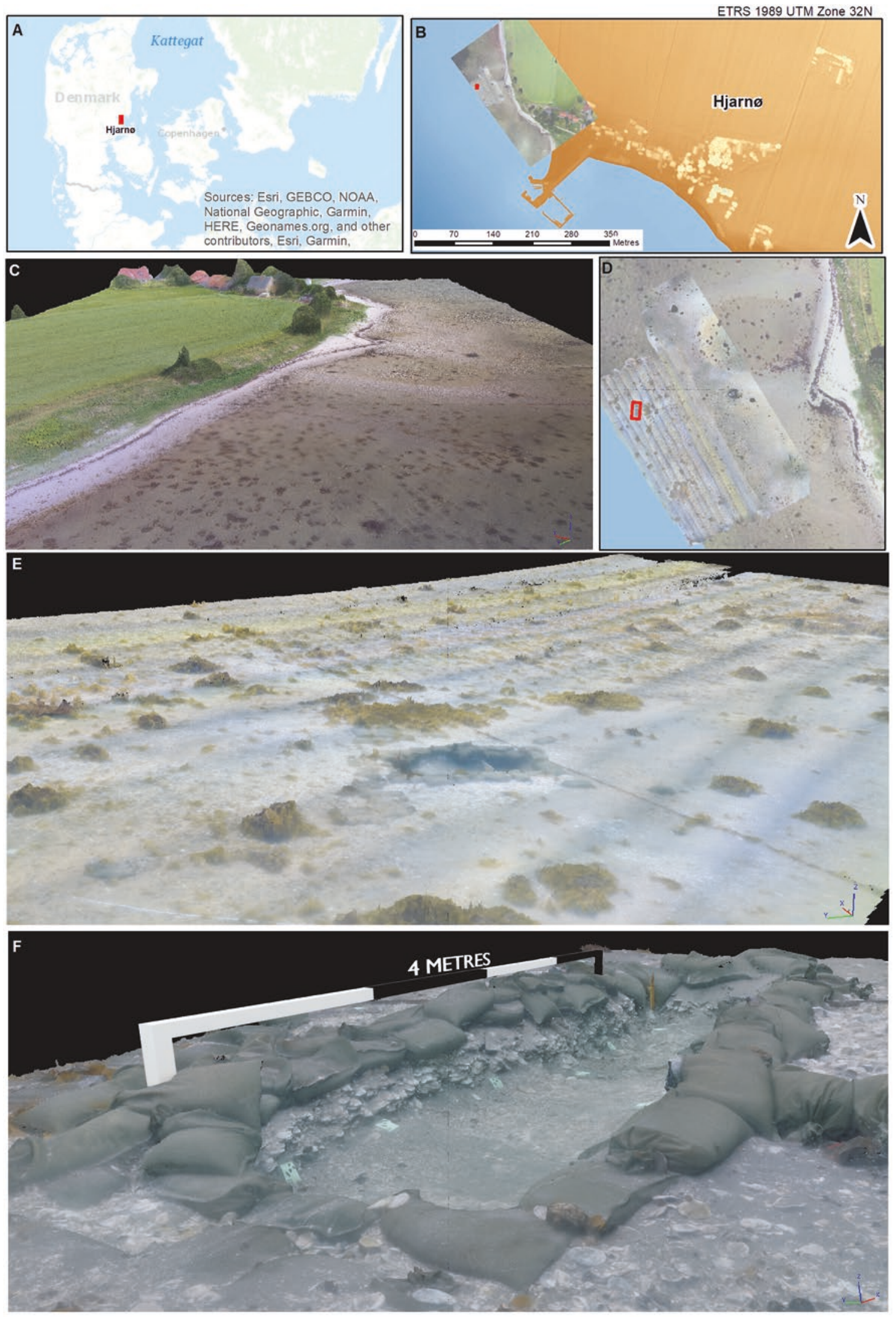

Fig. 14.7 (a) Orientation map showing the location of Hjarn $\varnothing$; (b) Site and landscape context, including aerial photogrammetric datasets, Lidar topography, and bathymetry. Location of excavated trench shown in red. Bathymetry dataset sourced from the Danish Geodata Agency. Contains data from the Data Security and Efficiency Board, DHM/
Surface (0.4 m grid); (c) Oblique view of aerial photogrammetry and coastal environment, looking southeast; (d) Locations of the aerial and underwater photogrammetric surveys; (e) Array photogrammetry survey showing excavated trench and context underwater; (f) Oblique view of excavated trench, facing north 


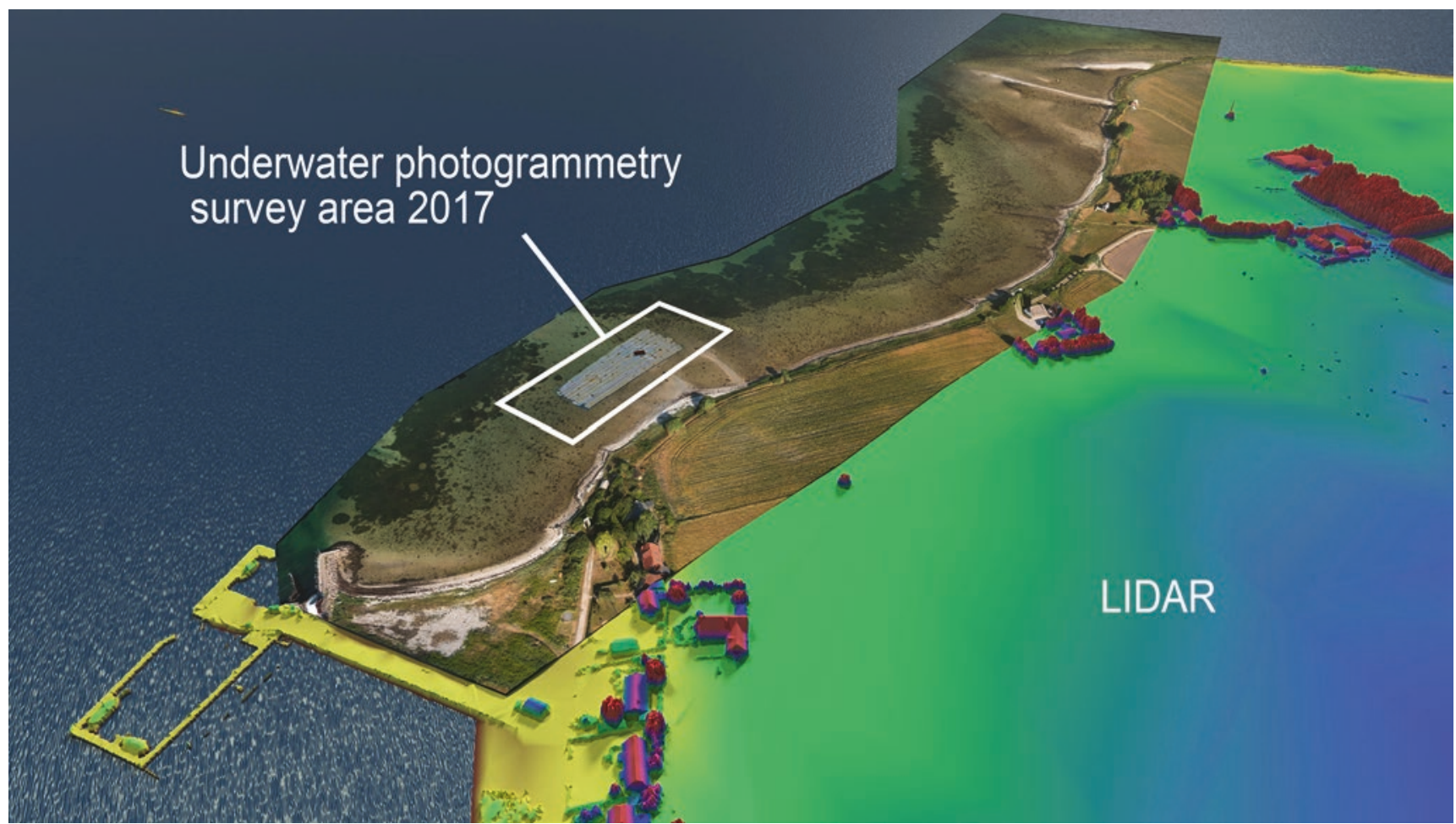

Fig. 14.8 A multi-dataset 3D working environment of the coastal prehistoric Hjarnø site and landscape, showing several layers of aerial and underwater photogrammetry, integrated with lidar data

cialised tasks in specific disciplines. (Wheatley and Gillings 2002: 241-242). Standalone general GIS packages only very recently allowed the integration of complex 3D models. As a result of the limitations of GIS packages previous attempts at 3D GIS for archaeology turned to custom developed, project specific platforms (e.g. Nebiker 2002; Wüst et al. 2004).

Within the last two decades development of 3D GIS platforms with the goal of integrating and visualizing complex $3 \mathrm{D}$ geometries and other data sources have been developed for the purpose of archaeology. An early example of pioneering work is the DILAS (Digital Landscape Server) platform (Nebiker 2002; Wüst et al. 2004). Another example of a custom platform for 3D GIS is the MayaArch3D project (Agugiaro et al. 2011a, b; Richards-Rissetto et al. 2012). Their project's approach to archaeological data organisation, visualization and analysis creates an interpretive window into the experiential aspects of past human behaviour as well as empirical analysis material culture (Agugiaro et al. 2011a). A considerable drawback of these purpose-built 3D GIS systems is that they require a specialized workflow using custom-coded software and complex database management system architecture. The project-specific, design makes them difficult to apply beyond their purpose-built archaeological research (Dell'Unto et al. 2015). In the context of such individual developments archaeologists called for a more general approach to 3D GIS, which led to a reexamining of the most modern features of commercial GIS packages (Dell'Unto et al. 2015; Ford 2004). A number of modern commercially available GIS systems exist that offer some form of true 3D data integration. These systems are often built with a variety of features offering different data management and analysis potentials.

Richards-Risetto (2017) recently asked 'What can GIS + 3D mean for landscape archaeology?' drawing attention to the historical tension and critique mainly by post-processual archaeologists to the application of GIS. Richards-Risetto points to the issues related to predictive modelling based on environmental data, the now ever-present debate around environmental determinism versus socio/cultural variables for locating, discovering and interpreting archaeological sites. The application of 3D GIS has an enormous potential for the study of maritime landscapes, bringing together 3D data into a realistically visualized geospatial environment and allowing analytical questions to be asked, empirically as well as providing rich visualizations of the data that allow more nuanced interpretations. Verhoeven $(2017,1021)$ points to the limited need for realistic appearance by the broader GIS community, which has historically limited the advancement for GIS packages to offer 3D visualizations natively. 3D modelling/animation software can fulfil many of the functions of 3D GIS but is generally limited to Euclidean space and incapable of dealing with geographic coordinate systems. There is currently a gap between these two technologies, but this is a clear example of convergence under- 
way. Wheatley and Gillings recognized this in 2002 when they wrote that 'it seems likely that the convergence of spatial technologies will continue beyond what we currently understand as GIS - in fact this is one of the principal reasons that we favour the term 'spatial technologies' over the more defined (and contested) 'Geographic Information Systems' (Wheatley and Gillings 2002, 216). Once the technical computing capacity can routinely support large scale 3D GIS platforms, archaeologists are on track to become some of the earliest adopters of this technology.

\subsection{Digital ‘Realities’}

Archaeologists are also adopting gaming engines as a form of data visualization and enhancement, which can be integrated into GIS (Richards-Rissetto 2017) or used for augmented reality (Eve 2014, 2017; Watterson 2015). The creation of interactive virtual spaces has become more accessible as the tools required evolve to meet the demands of a variety of users and applications. Watterson $(2015,20)$, points out that 'all image-making within archaeology involves implicit assumptions and explicit choices, but the context and technique behind the creation of these images and the ways they are consumed often obscure this process.' While digital tools and techniques are often in focus, the need to re-affirm the underlying rationale for how data are collected, adapted and presented should be consistently reviewed. Ewes (2014) recently discusses 'an opportunity to merge the real world with virtual elements of relevance to the past, including 3D models, soundscapes, smellscapes and other immersive data.' And suggests 'sophisticated deskbased GIS analyses can be experienced directly within the field and combined with a body-centred exploration of the landscape, creating an embodied GIS.'

The implementation of captured 3D data into navigable 3D spaces is now achievable within a reasonable budget and a team with the necessary specialist skills. The technological developments, which enable digital media experts and archaeologists to work together to rebuild the scenes, or the digital maritime cultural landscapes, allow for the further experiential or digital phenomenological approach to viewing and understanding past environments. Current technology stops short of a completely 'life-like' experience, however the direction and integration of these disciplines is heading toward a much more immersive experience. The creation of an interpretation of the past through virtual reality.

Watterson $(2015,19)$ has outlined the need for archaeologists to develop a more practical approach to addressing the issues through the development of method which consider the 'multi-layered, interpretive and ambiguous processes involved in archaeological interpretation.' Equally, the way someone experiences archaeology, whether in person or vir- tually, matters. A virtual experience of archaeology is not the opposite of a 'real' experience, though it may be described distinctly from a physical or experience (e.g. Falconer and Scott 2018). For the moment, people can still tell the difference between a virtual and a physically real experience, though this gap can only decrease over time. The technologies and methods for archaeological survey, recording and interpretation which have been discussed in this chapter continue to develop to the advantage of archaeologists worldwide. Conceptual models for understanding landscapes, their cultural modification and change over time, and need to apply and consider digital models of ever-expanding scale and quality. This has both an aesthetic appeal, but importantly, will be increasingly functional for the integrated interpretation of material culture and physical remains within physical and cultural landscapes.

Game engines are now commonly used to bring the past to life, facilitating both public engagement with past environments as well as providing a tool to allow archaeologists to immerse themselves in their study areas, provoking new questions and inspiring new directions in research. There are a variety of game engines available: Amazon's Lumberyard, Cry Engine, Epic's Unreal Engine 4 and Unity are used by small and large-scale game development teams. The flexible licensing costs of all listed game engines have made cutting edge real time interactive 3D game design technology available to teams with a variety of available budgets and skillsets. The example in Fig. 14.9 is a Unity-based VR environment that has been created of a coastal medieval castle in Scotland, at Ardtornish in the Sound of Mull in western Scotland. This castle is a typical power centre of the thalassocracies that dominated western Scotland in the later middle ages, centred on maritime castles but with a power founded on the maritime strength of huge fleets of highland galleys, also known as birlinns (Rixson 1988). This castle is in a maritime context, placed to oversee and control passage through a major seaway of the Sound of Mull. The maritime connections of the site are visible on the ground with evidence of possible boat haulages (noosts) visible in the intertidal zone around the castle. As with many maritime archaeological sites, it is difficult to appreciate the way this castle dominated and controlled this landscape and how the terrestrial power of the castle must have interacted with the maritime power of the ships that provided economic and military support. VR was employed to help understand the site in a more immersive way and to reconnect the two major elements of this power base, the castle and the ships. The castle was recorded in its landscape context in 3D using a DJI UAV (Figs. 14.1 and 14.9) including the intertidal zone. The castle itself was digitally reroofed and reconstructions of highland galleys were added to the VR environment. This simple reconstruction has shown how $3 \mathrm{D}$ recording is being taken beyond production of standard orthographic illustra- 

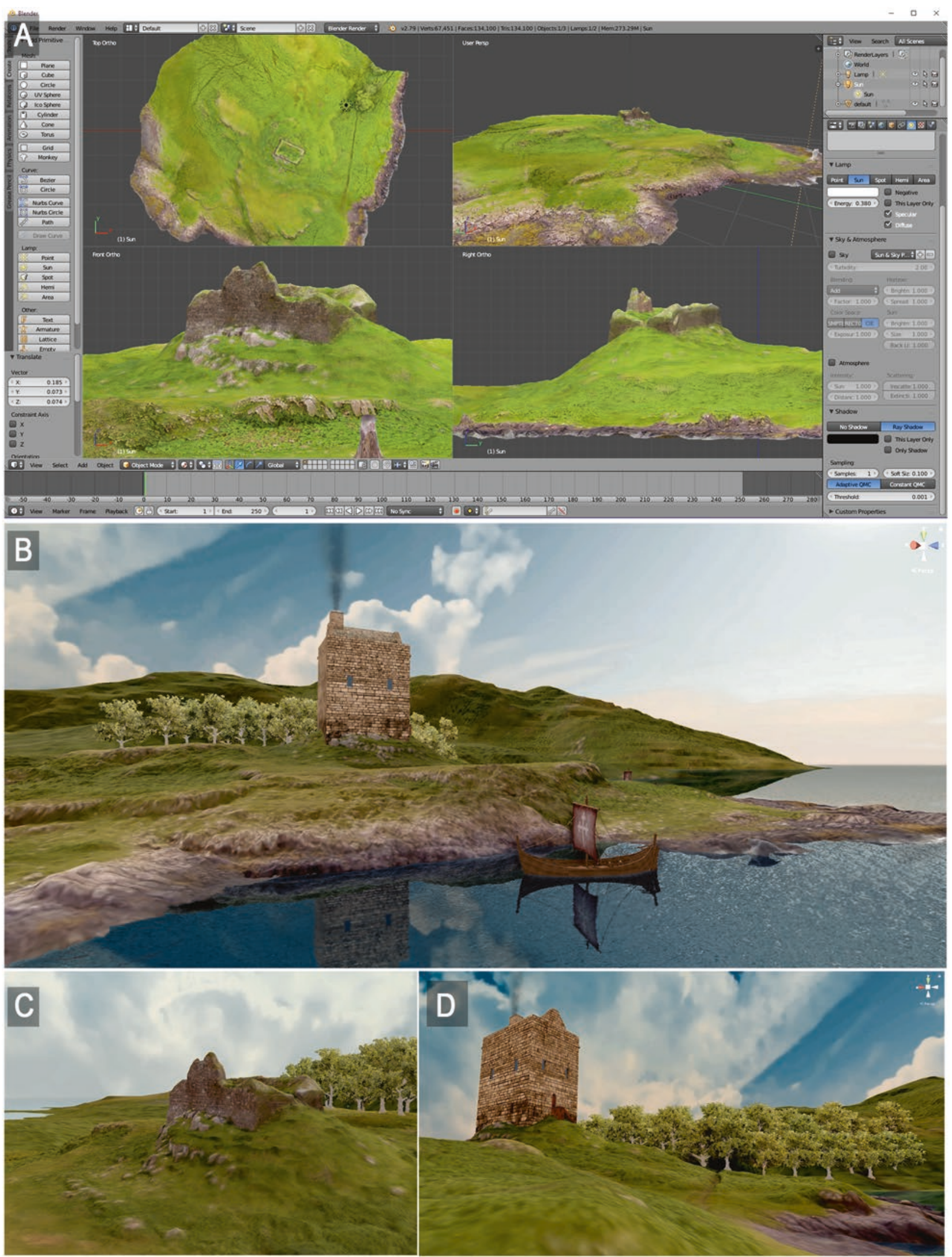

Fig. 14.9 Game Engines such as Unity allow for a photo-realistic 3D

An optimised 3D model created in Blender using photogrammetry data. virtual world to be created, based on real archaeological survey data. (a)

(b-d) The interactive 3D environment created in Unity, navigable using a game controller, keyboard, mouse and VR headset 
tions in reports and can produce assets for a wide variety of other meaningful archaeological outputs with minimal additional effort.

\subsection{Conclusions}

By advocating for a more technological approach to study maritime landscapes, we must be careful to avoid certain pitfalls. Relative to other forms of archaeological investigation, maritime archaeology has always had a particularly strong focus on the tools and technology and this has been a distraction from the archaeology itself. Critics of 3D recording, and representations of archaeological sites and cultural landscapes might be tempted to dismiss the technique as a gimmick; limiting the usefulness to simply a 'pretty picture.' While it is valid to point out that visual gratification does not necessarily make a scientific advancement, Verhoeven (2011, 67) is right: 'Let's face it-most people like 3D visualizations.' The reasons are not simply to do with aesthetic appeal, but rather 3D recording allows archaeologists to hold a landscape in their hands and to share their experience with others. It is also a space for enhanced archaeological interpretation, which builds on existing methods for site recording. The potential to create visual, experiential environments is also promising from an enhanced interpretation perspective as well as through visitor experience and interactivity in museums and educational sectors.

Virtual worlds can create a space for generating and testing new theories and developing those already accepted by the establishment. The interpretation of landscapes, features and setting in 3D has direct relevance to the broader discipline because archaeology deals with complex surfaces and examines traces of the human past in space. Archaeological interpretive mapping remains a main aim in the collection of such data. Rather than distracting from the subject, we agree with Chrysanthi et al. (2012, 9-10) who argue that one should become immersed in the interpretive process through a mastery of tools, and that digital tools function best when they are mastered to the extent that their own character is no longer the focus, having become an unnoticed extension or prosthesis of the maritime archaeologist.

Returning to the grand challenges facing digital archaeology and the reconsideration of MCL, the material and digital representations presented herein represent the state of the art and early adoption by archaeologists. Innovation is presented through the integrated approaches used to bridge the gap between land and sea, and particularly to record large, complex sites and landscapes through a variety of original and existing data. These are measurable, physically, in that sites can be recorded, scaled and mapped very accurately and exported into a system used in planning and development, especially GIS or other practical applications for outreach, such as VR. These relatively new techniques now present a genuine opportunity to inspire a new generation of stakeholders and end-users, not only specialists. The list of authors, all of whom have made a significant intellectual and practical contribution to the development of the material presented in this chapter also illustrates the collaborative nature of these methods and the international relevance is attested by the various case studies from around the world. In this respect, we hope to have showcased some of the advances within the discussion of Huggett et al.'s $(2018,44)$ 'fundamentals.' We also hope to have made an incremental advance by urging the reconsideration of a widely applied, but loosely defined theoretical framework, through a digital representation of physical landscapes, with renewed interest on the archaeological material and its relationship to landscapes over time.

For maritime archaeology, 3D capture of landscapes above and below the waterline offers the clearest, most analytical and most repeatable method for analysing and interpreting sites and contextualising material within their surrounding environments. Maritime archaeology stands to benefit, perhaps more so than any other sub-discipline for exactly these reasons; the waterline need no longer be a barrier to study the integrated cultural landscape, be that physical or cognitive. The results form a scalable, digital maritime landscape-an enhanced interpretive space in which to better examine the archaeological, anthropological, historical and environmental questions.

Acknowledgements The authors acknowledge the support of Historic Environment Scotland, Heritage Victoria, Wessex Archaeology, Flinders University (who provided an EHL Establishment Grant), Airborne Research Australia and the Australian Research Council through the Funding of the Deep History of Sea Country project (DP170100812). We thank two anonymous peer reviewers for their comments on an earlier draft which significantly contributed to improving this chapter.

\section{References}

Agugiaro G, Remondino F, Girardi G, Von Schwerin J, RichardsRissetto H, De Amicis R (2011a) A web-based interactive tool for multi-resolution 3D models of a Maya archaeological site. In: Proceedings of the 4th international workshop 3D-ARCH 2011: virtual reconstruction and visualization of complex architectures

Agugiaro G, Remondino F, Girardi G, Von Schwerin J, RichardsRissetto H, De Amicis R (2011b) Queryarch3D: querying and visualising 3D models of a Maya archaeological site in a web-based interface. Geoinformatics FCE CTU 6:10-17

Ash A (2007) The maritime cultural landscape of Port Willunga, South Australia, Flinders University Maritime Archaeology Monographs Series, vol 4. Archaeology, Flinders University, Adelaide 
Astrup PM, Skriver C, Benjamin J, Ward I, Stankewicz F, Ross P, McCarthy J, Baggaley P, Ulm S, Bailey G (2019) Underwater shell middens: excavation and remote sensing of a submerged Mesolithic shell midden at Hjarnø, Denmark. Journal of Island and Coastal Archaeology. (In Press)

Austin BT, Bateman J, Jeffrey S, Mitcham J, Niven K (2009) Marine remote sensing and photogrammetry: a guide to good practice. In: Niven K (ed) Archaeology data service. http://guides.archaeologydataservice.ac.uk/g2gp/VENUS_Toc. Accessed 21 Feb 2018

Bailey G, Momber G, Bell M, Tizzard L, Hardy K, Tidbury L, Benjamin J, Bicket A, Hale A (2019) Great Britain. In: Bailey G, Galanidou N, Joens H, Lueth F, Peeters H (eds) The archaeology of Europe's submerged landscapes. Springer, Cham

Ballin TB, White R, Richardson P, Neighbour T (2010) An early Mesolithic stone tool assemblage from clachan harbour, Raasay, Scottish Hebrides. Lithics: the Journal of the Lithic Studies Society 31:94-104

Bass G (1966) Archaeology under water. Praeger, New York

Benjamin J, Bicket A, Anderson D, Hale A (2014) A multi-disciplinary approach to researching the intertidal and marine archaeology in the outer Hebrides, Scotland. Journal of Island and Coastal Archaeology 9(3):400-424. https://doi.org/10.1080/15564894.2014.934490

Bewley R, Rączkowski W (2002) Aerial archaeology: developing future practice, vol 337. NATO Science Series A. NATO

Bicket A, Shaw G, Benjamin J (2017) Prospecting for Holocene palaeolandscapes in the Sound of Harris, Outer Hebrides. In: Bailey GN, Harff J, Sakellariou D (eds) Under the sea: archaeology and palaeolandscapes of the Continental Shelf, Coastal Research Library, vol 20. Springer, Heidelberg, pp 179-195. https://doi. org/10.1007/978-3-319-53160-1

Chen X, Lynch Ogan T (2017) China's emerging Silicon Valley: how and why has Shenzhen become a global innovation centre. Eur Financ Rev (December-January):55-62

Chirayath V, Earle SA (2016) Drones that see through waves-preliminary results from airborne fluid lensing for centimetre-scale aquatic conservation. Aquat Conserv Mar Freshwat Ecosyst 26(October 2015):237-250. https://doi.org/10.1002/aqc.2654

Chrysanthi A, Murrieta Flores P, Papadopoulos C (2012) Archaeological computing: towards prosthesis or amputation? In: Chrysanthi A, Murrieta Flores P, Papadopoulos C (eds) Thinking beyond the tool: archaeological computing and the interpretive process, BAR International Series 2344. Archaeopress, Oxford, pp 7-13

Colomina I, Molina P (2014) Unmanned aerial systems for photogrammetry and remote sensing: a review. ISPRS J Photogramm Remote Sens 92:79-97. https://doi.org/10.1016/j. isprsjprs.2014.02.013

Cowley D (ed) (2011) Remote sensing for archaeological heritage management. Proceedings of the 11th EAC Heritage Management Symposium, Reykjavik, Iceland, 25-27 March 2010. Occasiona Publication of the Aerial Archaeology Research Group, 3. Archaeolingua, Budapest, pp 11-14

Cowley D, Benjamin J, Martin C (2012) Aerial reconnaissance of maritime landscapes in Scotland-some preliminary observations on context, methodology and results. AARGnews 45(September):64-73

Cowley DC, Moriarty C, Geddes G, Brown GL, Wade T, Nichol CJ (2018) UAVs in context: archaeological airborne recording in a national body of survey and record. Drones 2(1):16pp. https://doi. org/10.3390/drones2010002

Delgado JP, Mendizábal T, Hanselmann FH, Rissolo D (2016) The maritime landscape of the Isthmus of Panamá. University Press of Florida, Gainesville

Dell'Unto N, Landeschi G, Leander Touati AM, Dellepiane M, Callieri M, Ferdani D (2015) Experiencing ancient buildings from a 3D GIS perspective: a case drawn from the Swedish Pompeii proj- ect. J Archaeol Method Theory 23:73-94. https://doi.org/10.1007/ s10816-014-9226-7

Doneus M, Verhoeven G, Fera M, Briese C, Kucera M, Neubauer W (2011) From deposit to point cloud - a study of low-cost computer vision approaches for the straightforward documentation of archaeological excavations. Geoinformatics FCE CTU 6:81-88. https:// doi.org/10.14311/gi.6.11

Doneus M, Doneus N, Briese C, Pregesbauer M, Mandlburger G, Verhoeven GJ (2013) Airborne laser bathymetry-detecting and recording submerged archaeological sites from the air. J Archaeol Sci 40(4):2136-2151

Drap P, Seinturier J, Long L (2003) Archaeological 3D modelling using digital photogrammetry and Expert System. The case study of Etruscan amphorae. In: 3IA 2003 - the sixth international conference on computer graphics and artificial intelligence, Limoges

Duel L (1969) Flights into yesterday: the story of aerial archaeology. St Martin's Press, New York

Ewes S (2014) Dead men's eyes: embodied GIS, mixed reality and landscape archaeology. Archaeopress, Oxford

Eve S (2017) The embodied GIS: using mixed reality to explore archaeological landscapes. Internet Archaeol 44(44). https://doi. org/10.11141/ia.44.3

Falconer L, Scott C (2018) Phenomenology and phenomenography in virtual worlds: an example from archaeology. In: Falconer L, Gil Ortega MC (eds) Virtual worlds: concepts, applications and future directions. Nova Science Publishers, New York, pp 1-38

Firth A (2011) Marine geophysics: integrated approaches to sensing the seabed. In: Cowley D (ed) Remote sensing for archaeological heritage management, EAC Occasional Paper No 5. Europae Archaeologia Consilium, Brussels, pp 129-140

Fischer A (1995) Man and sea in the Mesolithic: coastal settlements above and below the sea. Oxbow Books, Oxford

Flatman J (2011) Places of special meaning: Westerdahl's comet, "agency," and the concept of the "Maritime Cultural Landscape". In: Ford B (ed) The archaeology of maritime landscapes. When the land meets the sea, ACUA and SHA Series, vol 2. Springer, New York

Ford A (2004) The visualisation of integrated 3D petroleum datasets in ArcGIS. In: Proceedings of 24th ESRI user conference. pp 1-11

Ford B (2018a) The shore is a bridge: the maritime cultural landscape of Lake Ontario. Texas A\&M University Press, College Station

Ford B (2018b) Concluding remarks about the MCL symposium. In: Wyatt B (ed) Volume 1: presentation papers. Proceedings of the maritime cultural landscape symposium, University of WisconsinMadison, 14-15 October 2015

Garstki K (2017) Virtual representation: the production of 3D digital artifacts. J Archaeol Method Theory 24(3):726-750. https://doi. org/10.1007/s10816-016-9285-Z

Gately I, Benjamin J (2018) Archaeology hijacked: addressing the historical misappropriations of maritime and underwater archaeology. J Marit Archaeol 13(1):15-35. https://doi.org/10.1007/ s11457-017-9177-8

Georgopoulos A, Agrafiotis P (2012) Documentation of a submerged monument using improved two media techniques. Proceedings of the 2012 18th international conference on virtual systems and multimedia, VSMM 2012: virtual systems in the information society. pp $173-180$

Green J, Gainsford M (2003) Evaluation of underwater surveying techniques. Int J Naut Archaeol 32:252-261. https://doi.org/10.1016/j. ijna.2003.08.007

Hacker JM, Pfennigbauer M (2017) Pushing lidar to the limitshigh-resolution bathymetric lidar from slow-flying aircraft. GIM International (Feb), pp 29-31

Hacker JM, Bannehr L, Junkermann W, Neininger B, Lieff W, McGrath AJ; Zubot D, Zulueta R (2018a) Mind the gap between drones and 
traditional airborne platforms. Proceedings of the 2018 NRM science conference, Adelaide

Hacker JM, Brooks A, Spencer J (2018b) Mapping erosion gullies 20 minutes in the air or 2 weeks in the gullies. Proceedings of the 2018 NRM science conference, Adelaide

Hardy K, Benjamin J, Bicket A, McCarthy J, Ballin T (2015) Lub Dubh Aird: a seamless Mesolithic landscape in northwest Scotland. Proc Soc Antiqu Scotl 145:27-39

Harris L (2017) Sea ports and sea power: African maritime cultural landscapes. Springer, Cham

Henderson JC, Pizarro O, Johnson-Roberson M, Mahon I (2013) Mapping submerged archaeological sites using stereo-vision photogrammetry. Int J Naut Archaeol 42(2):243-256. https://doi. org/10.1111/1095-9270.12016

Huggett J, Reilly P, Lock G (2018) Whither digital archaeological knowledge? The challenge of unstable futures. J Comput Appl Archaeol 1(1):42-54. https://doi.org/10.5334/jcaa.7

Kotilainen AT, Kaskela AM (2017) Comparison of airborne LiDAR and shipboard acoustic data in complex shallow water environments: filling in the white ribbon zone. Mar Geol 385:250-259. https://doi. org/10.1016/j.margeo.2017.02.005

Kreij A, Scriffignano J, Rosendahl D, Nagel T, Ulm S (2018) Aboriginal stone-walled intertidal fishtrap morphology, function and chronology investigated with high-resolution close-range Unmanned Aerial Vehicle photogrammetry. J Archaeol Sci 96:148-161. https://doi. org/10.1016/j.jas.2018.05.012

Liarokapis F, Kouřil P, Agrafiotis P, Demesticha S, Chmelík J, Skarlatos D (2017) 3D Modelling and mapping for virtual exploration of underwater archaeology assets. Int Arch Photogramm Remote Sens Spat Inf Sci Arch XLII-2/W3(March):425-431. https://doi. org/10.5194/isprs-archives-XLII-2-W3-425-2017

Maas HG (2015) On the accuracy potential in underwater/multimedia photogrammetry. Sensors (Switzerland) 15(8):18140-18152

McCarthy J (2014) Multi-image photogrammetry as a practical tool for cultural heritage survey and community engagement. J Archaeol Sci 43:175-185. https://doi.org/10.1016/j.jas.2014.01.010

McCarthy J, Benjamin J (2014) Multi-image photogrammetry for underwater archaeological site recording: an accessible, diver-based approach. J Marit Archaeol 9(1):95-114. https://doi.org/10.1007/ s11457-014-9127-7

McCarthy J, Benjamin J (2018) Project SAMPHIRE: crowd sourcing maritime archaeology data off Scotland's West Coast. J Island Coast Archaeol, 24pp. https://doi.org/10.1080/15564894.2017.1387620

McCarthy J, Robertson P, Mackay E (2015) Discovery and survey of a 17 th-18th century shipwreck near Drumbeg, NW Scotland: an initial report. Int J Naut Archaeol 44(1):202-208. https://doi. org/10.1111/1095-9270.12087

Menna F, Nocerino E, Troisi S, Remondino F (2015) Joint alignment of underwater and above-the-water photogrammetric 3D models by independent models adjustment. Int Arch Photogramm Remote Sens Spat Inf Sci XL-5/W5:143-151. https://doi.org/10.5194/ isprsarchives-XL-5-W5-143-2015

Morgan C, Wright H (2018) Pencils and pixels: drawing and digital media in archaeological field recording. J Field Archaeol 43(2):136151. https://doi.org/10.1080/00934690.2018.1428488

Mount R (2005) Acquisition of through-water aerial survey images: surface effects and the prediction of sun glitter and subsurface illumination. Photogramm Eng Remote Sens 71(12):1407-1415

Nebiker S (2002) Design and implementation of the high-performance 3D digital landscape Server DILAS. Int Arch Photogramm Remote Sens Spat Inf Sci 34(4):391-394

Neininger B, Hacker JM (2011) Manned or unmanned - does this really matter? In: Eisenbeiss H, Kunz M, Ingensand H. Proceedings of the international conference on unmanned aerial vehicles in geomatics (UAV-g), Zurich, Switzerland, 14-16 September 2011, vol XXXVIII-1/C22. pp 223-228
Olson BR, Ryan A, Placchetti JQ, Killebrew AE (2013) The Tel Akko total archaeology project (Akko, Israel): assessing the suitability of multi-scale 3D field recording in archaeology. J Field Archaeol 38(3):244-262. https://doi.org/10.1179/0093469013Z.000000000 $56 \mathrm{~s}$

Remondino F, Barazzetti L, Nex F, Scaioni M, Sarazzi D (2011) UAV photogrammetry for mapping and $3 \mathrm{~d}$ modeling - current status and future perspectives. The international archives of the photogrammetry, remote sensing and spatial information sciences, vol XXXVIII-1/C22, pp 25-31. ISPRS Zurich 2011 Workshop, Zurich, Switzerland, 14-16 September 2011

Remondino F (2011) Heritage recording and 3D modeling with photogrammetry and 3D scanning. Remote Sens 3(6):1104-1138. https:// doi.org/10.3390/rs3061104

Richards-Rissetto H (2017) What can GIS + 2D mean for landscape archaeology? J Archaeol Sci 84:10-21. https://doi.org/10.1016/j. jas.2017.05.005s

Richards-Rissetto H, Remondino F, Agugiaro G, Von Schwerin J, Robertsson J, Girardi G (2012) Kinect and 3D GIS in archaeology. Proceedings of the 18th international conference on Virtual Systems and Multimedia (VSMM), Milan, 2012. pp 331-337. https://doi. org/10.1109/VSMM.2012.6365942

Riley DN (1982) Aerial archaeology in Britain. Shire Publications, Princes Risborough

Rixson D (1988) The West Highland galley. Birlinn, Edinburgh

Roberts A, Colwell-Pasch C, Davison L, Benjamin J (2015) Leven Lass historic shipwreck, Phillip Island Victoria: 2015 maritime archaeology field school technical report. Unpublished Technical Report Prepared for Heritage Victoria, Melbourne

Rönnby J (2007) Maritime durées: long-term structures in a coastal landscape. J Marit Archaeol 2(2):65-82. https://doi.org/10.1007/ s11457-007-9021-7

Skriver C, Borrup P, Astrup PM (2017) Hjarnø Sund: an eroding Mesolithic site and the tale of two paddles. In: Bailey GN, Harff J, Sakellariou D (eds) Under the sea: archaeology and palaeolandscapes of the Continental Shelf, Coastal Research Library, vol 20. Springer, Heidelberg, pp 131-143. https://doi. org/10.1007/978-3-319-53160-1

Society for American Archaeology (2016) The SAA archaeological record (March) 16(2)

Spring AP, Peters C (2014) Developing a low cost 3D imaging solution for inscribed stone surface analysis. J Archaeol Sci 52:97-107. https://doi.org/10.1016/j.jas.2014.08.017

Stewart DJ (2011) Preface: putting the wheels on maritime cultural landscape studies. In: Ford B (ed) The archaeology of maritime landscapes, When the land meets the sea, ACUA and SHA series, vol 2. Springer, New York, pp vii-viii

Tait E, Laing R, Grinnall A, Burnett S, Isaacs J (2015) (Re)presenting heritage: laser scanning and $3 \mathrm{D}$ visualisations for cultural resilience and community engagement. J Inf Sci 42(3):420-433. https://doi. org/10.1177/0165551516636306

Tuddenham DB (2010) Maritime cultural landscapes: maritimity and quasi objects. J Marit Archaeol 5(1):5-16. https://doi.org/10.1007/ s11457-010-9055-0

Uldum O, Benjamin J, McCarthy J, Feulner F, Lübke H (2017) The Late Mesolithic site of Falden, Denmark: results from underwater archaeological fieldwork and a strategy for capacitybuilding based on the SPLASHCOS mission. In: Bailey GN, Harff J, Sakellariou D (eds) Under the sea: archaeology and palaeolandscapes of the Continental Shelf, Coastal Research Library, vol 20. Springer, Heidelberg, pp 65-84. https://doi. org/10.1007/978-3-319-53160-1

Verhoeven G (2011) Taking computer vision aloft-archaeological three-dimensional reconstructions from aerial photographs with PhotoScan. Archaeol Prospect 18:76-73. https://doi.org/10.1002/ $\operatorname{arp} .399$ 
Verhoeven G (2017) Mesh is more-using all geometric dimensions for the archaeological analysis and interpretative mapping of 3D surfaces. J Archaeol Method Theory 24(4):999-1033. https://doi. org/10.1007/s10816-016-9305-z

Watterson A (2015) Beyond digital dwelling: re-thinking interpretive visualisation in archaeology. Open Archaeol 1:119-130. https://doi. org/10.1515/opar-2015-0006

Westerdahl C (1992) The maritime cultural landscape. Int J Naut Archaeol 21(1):5-14. https://doi.org/10.1111/j.1095-9270.1992. tb00336.x

Westerdahl C (2008) Boats apart. building and equipping an iron-age and early-medieval ship in northern Europe. Int J Naut Archaeol 37(1):17-31. https://doi.org/10.1111/j.1095-9270.2007.00170.x
Westerdahl C (2011) The maritime cultural landscape. In: Catsambis A, Ford B, Hamilton DL (eds) The Oxford handbook of maritime archaeology. Oxford University Press, Oxford, pp 733-762. https:// doi.org/10.1093/oxfordhb/9780199336005.013.0032

Wheatley D, Gillings M (2002) Spatial technology and archaeology: the archaeological applications of GIS. Taylor \& Francis, London

Wüst T, Nebiker S, Landolt R (2004) Applying the 3D GIS DILAS to archaeology and cultural heritage projects-requirements and first results. Int Arch Photogramm Remote Sens Spat Inf Sci XXXV(B5):407-412

Yamafune K, Torres R, Castro F (2016) Multi-Image photogrammetry to record and reconstruct underwater shipwreck sites. J Archaeol Method Theory 24(3):703-725. https://doi.org/10.1007/ s10816-016-9283-1

Open Access This chapter is licensed under the terms of the Creative Commons Attribution 4.0 International License (http://creativecommons. org/licenses/by/4.0/), which permits use, sharing, adaptation, distribution and reproduction in any medium or format, as long as you give appropriate credit to the original author(s) and the source, provide a link to the Creative Commons licence and indicate if changes were made.

The images or other third party material in this chapter are included in the chapter's Creative Commons licence, unless indicated otherwise in a credit line to the material. If material is not included in the chapter's Creative Commons licence and your intended use is not permitted by statutory regulation or exceeds the permitted use, you will need to obtain permission directly from the copyright holder. 